Virginia Commonwealth University VCU Scholars Compass

\title{
Conserved Vibrational Coherence in the Ultrafast Rearrangement of 2-Nitrotoluene Radical Cation
}

Derrick Ampadu Boateng

VCU

Mi'Kayla D. Word

VCU

Lavrenty Gutsev

VCU, lgutsev@outlook.com

Puru Jena

Virginia Commonwealth University

Katharine M. Tibbetts

VCU,kmtibbetts@vcu.edu

Follow this and additional works at: https://scholarscompass.vcu.edu/chem_pubs

Part of the Chemistry Commons

\section{Downloaded from}

https://scholarscompass.vcu.edu/chem_pubs/91

This Article is brought to you for free and open access by the Dept. of Chemistry at VCU Scholars Compass. It has been accepted for inclusion in Chemistry Publications by an authorized administrator of VCU Scholars Compass. For more information, please contact libcompass@vcu.edu. 


\title{
Conserved Vibrational Coherence in the
}

\section{Ultrafast Rearrangement of 2-Nitrotoluene Radical Cation}

Derrick Ampadu Boateng, ${ }^{\dagger}$ Mi'Kayla D. Word,${ }^{\dagger}$ Lavrenty G. Gutsev, ${ }^{\ddagger}$ Puru Jena, ${ }^{\ddagger}$ and Katharine Moore Tibbetts*,†

$\dagger$ Department of Chemistry, Virginia Commonwealth University, Richmond, VA 23284 $\ddagger$ Department of Physics, Virginia Commonwealth University, Richmond, VA 23284

E-mail: kmtibbetts@vcu.edu

Phone: (804)-828-7515

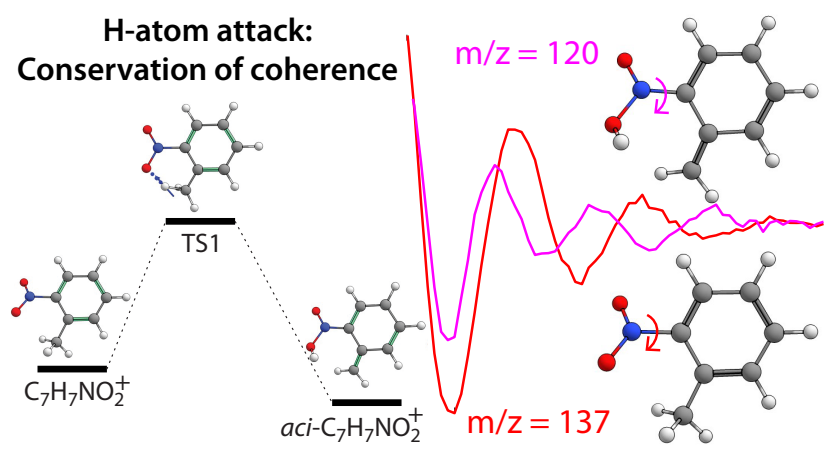

\begin{abstract}
2-nitrotoluene (2-NT) is a good model for both photolabile protecting groups for organic synthesis and the military explosive 2,4,6-trinitrotoluene (TNT). In addition to the direct $\mathrm{C}-\mathrm{NO}_{2}$ bond-cleavage reaction that initiates detonation in TNT, 2-NT undergoes an H-atom attack reaction common to the photolabile 2-nitrobenzyl group,
\end{abstract}


which forms the aci-nitro tautomer. In this work, femtosecond pump-probe measurements with mass spectrometric detection and density functional theory (DFT) calculations demonstrate that the initially-prepared vibrational coherence in 2 -NT radical cation $\left(2-\mathrm{NT}^{+}\right)$is preserved following $\mathrm{H}$-atom attack. Strong-field adiabatic ionization is used to prepare $2-\mathrm{NT}^{+}$, which can overcome a modest $0.76 \mathrm{eV}$ energy barrier to $\mathrm{H}$ atom attack to form the aci-nitro tautomer as soon as $\sim 20-60 \mathrm{fs}$ after ionization. Once formed, the aci-nitro tautomer spontaneously loses $-\mathrm{OH}$ to form $\mathrm{C}_{7} \mathrm{H}_{6} \mathrm{NO}^{+}$, which exhibits distinctly faster oscillations in its ion yield (290 fs period) as compared to the $2-\mathrm{NT}^{+}$ion (380 fs period). The fast oscillations are attributed to the coherent torsional motion of the aci-nitro tautomer, which has a significantly faster computed torsional frequency $\left(86.9 \mathrm{~cm}^{-1}\right)$ than the $2-\mathrm{NT}^{+}$ion $\left(47.9 \mathrm{~cm}^{-1}\right)$. Additional DFT calculations identify reaction pathways leading to the formation of the dissociation products $\mathrm{C}_{7} \mathrm{H}_{6} \mathrm{NO}^{+}, \mathrm{C}_{7} \mathrm{H}_{7}^{+}$, and $\mathrm{C}_{6} \mathrm{H}_{6} \mathrm{~N}^{+}$. Collectively, these results reveal a rich picture of coherently- and incoherently-driven dissociation pathways in $2-\mathrm{NT}^{+}$.

\section{Introduction}

The photolabile 2-nitrobenzyl functional group has a number of applications including as a protecting group in organic synthesis, ${ }^{1}$ as a precursor in the synthesis of DNA microarrays ${ }^{2}$ and in caged compounds for biomolecule encapsulation. ${ }^{3}$ In addition to these applications, the 2-nitrobenzyl group is found in the military explosive 2,4,6-trinitrotoluene (TNT), ${ }^{4}$ which

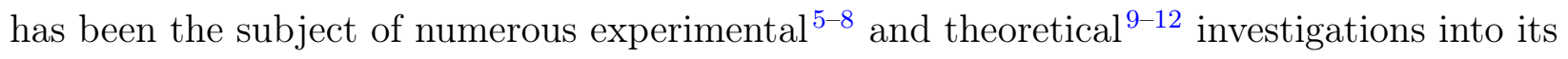
dissociation pathways. The nitrotoluene (NT) isomers 2-, 3-, and 4-NT are often used as model compounds for TNT, and their photodissociation pathways have been studied for

decades using mass spectrometric detection of cationic photoproducts. ${ }^{5,13-22}$ These studies have demonstrated clear differences in reaction pathways of 2-NT as compared to 3- and 4-NT due to the proximity of the $\mathrm{CH}_{3}$ and $\mathrm{NO}_{2}$ groups in the 2-nitrotoluyl moiety. 
Upon ionization, all three NT isomers undergo direct homolysis of the weak $\mathrm{C}-\mathrm{NO}_{2}$ bond (Scheme 1), producing the $\mathrm{C}_{7} \mathrm{H}_{7}{ }^{+}$ion with $\mathrm{m} / \mathrm{z}=91$ in mass spectrometry experiments. ${ }^{5,15-22}$ The $\mathrm{C}-\mathrm{NO}_{2}$ cleavage is also the primary initiator of detonation in TNT. ${ }^{9}$

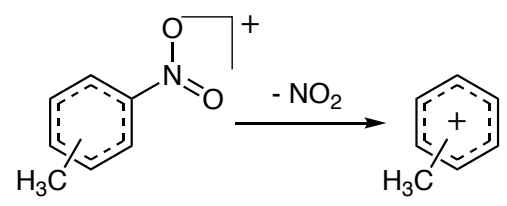

Scheme 1: $\mathrm{C}-\mathrm{NO}_{2}$ homolysis in NTs.

The 3- and 4-NT cations also undergo nitro-nitrite rearrangement (NNR, Scheme 2), leading to the loss of $\mathrm{NO}$ and the formation of $\mathrm{C}_{7} \mathrm{H}_{7} \mathrm{O}^{+}$ions with $\mathrm{m} / \mathrm{z}=107.5,16-18,20,22$ The $\mathrm{m} / \mathrm{z}=$ 107 ion is formed at significantly reduced yields in 2 -NT, ${ }^{5,17,18}$ indicating that NNR is not energetically favorable in this isomer.

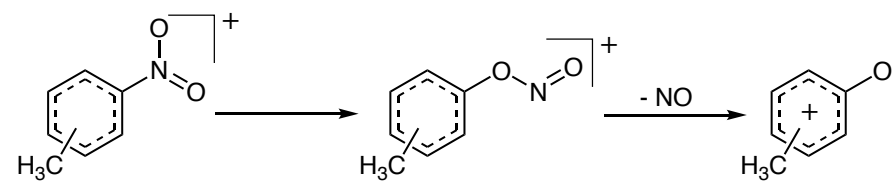

Scheme 2: NNR in 3- and 4-NT.

Instead of NNR, the 2-NT cation undergoes a unique process called aci-rearrangement wherein the aliphatic hydrogen migrates to the nitro group, which results in the formation of an aci-nitro tautomer in a process called ortho attack (Scheme 3). The aci-nitro tautomer loses $\mathrm{OH}$, forming $\mathrm{C}_{7} \mathrm{H}_{6} \mathrm{NO}^{+}$ions with $\mathrm{m} / \mathrm{z}=120$, which can subsequently lose CO to produce $\mathrm{C}_{6} \mathrm{H}_{6} \mathrm{~N}^{+}$with $\mathrm{m} / \mathrm{z}=92 .{ }^{5,13,14,16-18,21}$

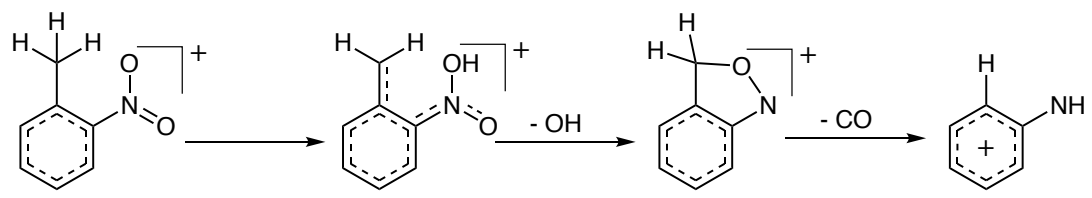

Scheme 3: Aci-rearrangement and sequential dissociation in 2-NT.

The aci-rearrangement reaction in neutral 2-NT was first reported in $1962^{23}$ and was determined to be the initial step in the sequential dissociation of 2 -NT cation to form $\mathrm{m} / \mathrm{z}=120$ 
and $\mathrm{m} / \mathrm{z}=92$ ions in $1965 .{ }^{13}$ More recently, theoretical studies have proposed mechanisms for this sequential dissociation pathway in neutral 2-NT ${ }^{24-26}$ and $2-\mathrm{NT}$ cation ${ }^{21}$ in the gas phase. However, the reaction dynamics and their timescales involved are still only partially understood.

The ultrafast dynamics of the aci-rearrangement in neutral 2-NT and other 2-nitrobenzyl compounds have been studied in solution phase using time-resolved pump-probe experiments with femtosecond laser pulses. ${ }^{27,28}$ Upon excitation of 2 -NT to the $\pi \pi^{*}\left(\mathrm{~S}_{2}\right)$ state, aci-rearrangement occurs following relaxation to the $n \pi^{*}\left(\mathrm{~S}_{1}\right)$ state on a timescale of 10 ps or after intersystem crossing to the triplet manifold on a timescale of 1300 ps. $^{27}$ While these experiments provide key insights into the aci-rearrangement dynamics in neutrals, the solution-phase timescales may be affected by solvent interactions and subsequent molecular dissociation pathways have not been explored. ${ }^{27,28}$ Additionally, no aci-rearrangement or subsequent dissociation timescales have been reported in 2-NT cation. As a result, knowledge of both the aci-rearrangement and subsequent dissociation mechanisms may be gained through femtosecond pump-probe measurements on the isolated 2-NT cation.

Pump-probe experiments have provided extensive insight into the dissociation dynamics of isolated organic cations including halogenated methanes, ${ }^{29-32}$ alkyl aryl ketones ${ }^{33-36}$ azobenzene, ${ }^{37,38}$ dimethyl methylphosphonate, ${ }^{39}$ and 3 - and $4-\mathrm{NT} .{ }^{22}$ In these molecules, ionization with a strong-field femtosecond pump pulse results in the formation of a coherent superposition of vibrational states, or "wave packet," in the ground electronic state of the cation. Wave packet excitation to a dissociative ionic excited state by the time-delayed probe pulse results in oscillations in the parent and fragment ion yields as a function of probe delay with period corresponding to the coherently excited vibrational mode. ${ }^{22,29-39}$ Our recent pump-probe study of 3 - and 4 -NT cations ${ }^{22}$ determined that wave packets are formed along an in-plane bending mode in (216 fs period, $160 \mathrm{~cm}^{-1}$ ) 3-NT cation and the $\mathrm{C}-\mathrm{NO}_{2}$ torsional mode (470 fs period, $70 \mathrm{~cm}^{-1}$ ) in 4-NT cation. Coherent excitation with the probe pulse was found to drive the $\mathrm{C}-\mathrm{NO}_{2}$ homolysis pathway in Scheme 1. 
To answer outstanding questions about the dynamical timescales involved in $\mathrm{H}$-atom attack and subsequent dissociation pathways in 2-NT, this work reports the first femtosecond pump-probe measurements on the isolated 2-NT cation. We use near-infrared (1300 $\mathrm{nm}$ ) laser pulses for ionization because strong-field excitation with wavelengths in the range of $\sim 1200-1600 \mathrm{~nm}$ induces predominantly adiabatic electron-tunneling ionization instead of nonadiabatic multiphoton ionization, which dominates at the Ti:Sapphire wavelength of $800 \mathrm{~nm} .{ }^{40,41}$ Adiabatic ionization with near-infrared pulses has been widely used to prepare a high population of ground-electronic state polyatomic cations as vibrational wave packets, ${ }^{22,35,36,38,39}$ and produces significant improvements in the resolution of ion-yield os-

cillations in pump-probe experiments as compared to using $800 \mathrm{~nm}$ for ionization. ${ }^{35,39} \mathrm{In}$ terpretation of the experimental dissociation dynamics is supported by a series of density functional theory (DFT) calculations of the energies, relaxation pathways, and vibrational frequencies of the 2-NT cation and its aci-nitro tautomer, along with molecular dynamics simulations to estimate the timescale of H-atom attack. We will show that coherent torsional wave packet motion is conserved following $\mathrm{H}$-atom attack, with the aci-nitro tautomer of 2NT cation producing distinct dynamics in the $-\mathrm{OH}$ loss product at $\mathrm{m} / \mathrm{z}=120$ as compared to other ions. These results open up the possibility of coherent control over the reactions of photolabile 2-nitrobenzyl protecting groups.

\section{Methods}

\section{$2.1 \quad$ Experiment}

Portions of the experimental setup have been described in detail in our previous publications: ${ }^{22,39,42,43}$ here we describe the modifications to produce tunable probe pulses in the visible range. A commercial Ti:Sapphire regenerative amplifier (Astrella, Coherent, Inc.) producing $30 \mathrm{fs}, 800 \mathrm{~nm}, 2.2 \mathrm{~mJ}$ pulses is used to pump an optical parametric amplifier (OPA, TOPAS Prime) to produce $1200-1600$ nm, 20 fs, $300 \mu \mathrm{J}$ pulses. Figure 1 shows 
a schematic diagram of the beam paths. A 50:50 (r:t) beam splitter placed after the OPA output splits the beam into pump and probe lines. The pump beam passes through a $\lambda / 2$ wave plate and Wollaston polarizer for attenuation and is then expanded by a telescope made of spherical mirrors with $f=-10 \mathrm{~cm}$ and $f=50 \mathrm{~cm}$ to increase the beam diameter (measured with the knife-edge method) from $4.5 \mathrm{~mm}$ to $22.0 \mathrm{~mm}$. The expanded beam has maximum energy ranging from $50-150 \mu \mathrm{J}$ depending on the wavelength, and can reach focal peak intensities exceeding $4 \times 10^{14} \mathrm{~W} \mathrm{~cm}^{-2} .{ }^{43}$ The probe beam is directed to a retroreflector placed on a motorized translation stage (ThorLabs, Inc), attenuated with a variable neutral density filter, and frequency-doubled with a $\beta$-barium borate (BBO) crystal. The maximum probe energy is $10 \mu \mathrm{J}$ at $650 \mathrm{~nm}$. With a home built frequency-resolved optical gating (FROG) setup, ${ }^{44}$ the duration of the pump and probe were measured to be 18 fs and 25 fs, respectively (Supporting Information, Figure S1). Pump and probe beams are recombined on a dichroic mirror and focused with a $f=20 \mathrm{~cm}$ fused silica biconvex lens into an ultrahigh vacuum chamber (base pressure $2 \times 10^{-9}$ torr) coupled to a custom-built linear time-of-flight mass spectrometer (TOFMS) described previously. ${ }^{42,43}$

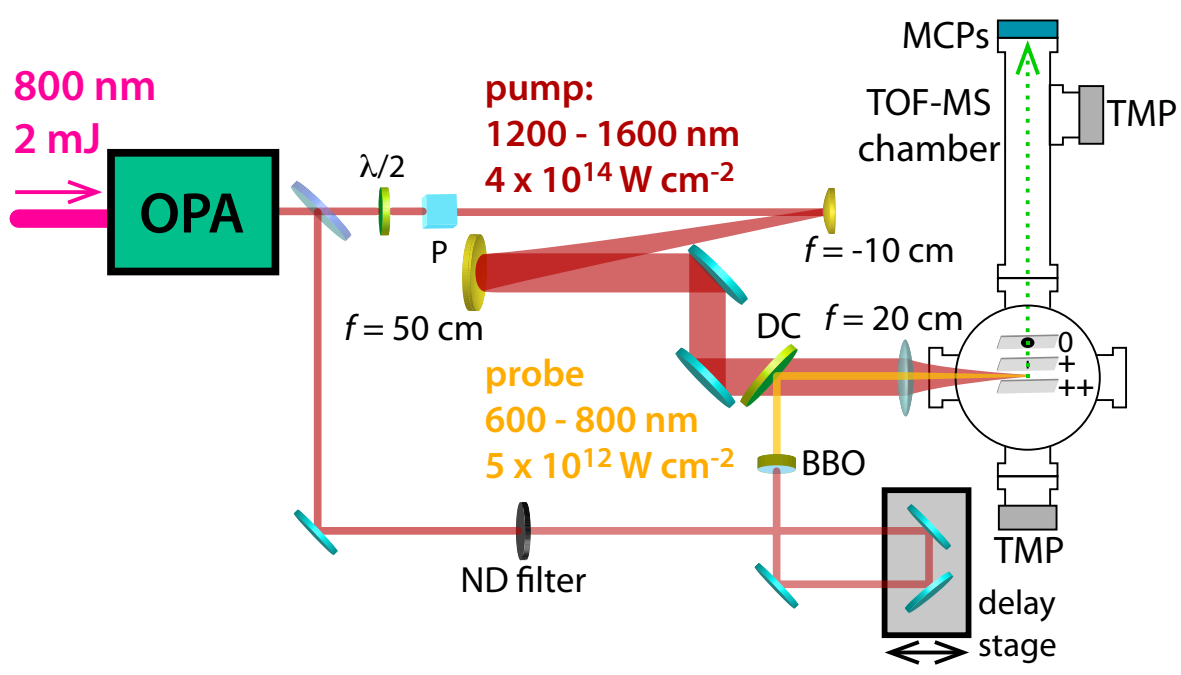

Figure 1: Schematic of pump and probe beam paths. $\lambda / 2$ : half wave plate; P: Wollaston polarizer; ND: neutral density; BBO: $\beta$-barium borate crystal; DC: dichroic mirror.

Pump-probe measurements on 2-NT were taken with a pump wavelength of $1300 \mathrm{~nm}$ at intensities of $1 \times 10^{14} \mathrm{~W} \mathrm{~cm}^{-2}$ and $2 \times 10^{14} \mathrm{~W} \mathrm{~cm}^{-2}$, as determined by the yield of $\mathrm{Xe}^{n+}$ 
ions using the method of Hankin. ${ }^{45}$ The $650 \mathrm{~nm}$ probe intensity was determined through measurement of the energy using a pyroelectric power meter (PM-USB, Coherent, Inc.) and the beam waist using a CMOS camera (DCC1645M, ThorLabs, Inc.). The beam waist and Rayleigh range are $38 \mu \mathrm{m}$ and $10 \mathrm{~mm}$, respectively (Supporting Information, Figure S2), producing estimated peak intensities ranging from $9 \times 10^{11}-5 \times 10^{12} \mathrm{~W} \mathrm{~cm}^{-2}$ at pulse energies of $1-6 \mu \mathrm{J}$. The pump-probe delay was scanned from -500 fs (probe before pump) to $+8000 \mathrm{fs}$ in steps of $20 \mathrm{fs}$. The 2-NT sample (99\%, Sigma-Aldrich) is used without further purification and introduced into the TOFMS at a pressure of $1.2 \times 10^{-7}$ torr measured near the microchannel plate (MCP) detector. Mass spectra of 2-NT taken at each pump-probe delay and averaged over 1000 laser shots were recorded with a $1 \mathrm{GHz}$ digital oscilloscope (LeCroy WaveRunner 610Zi). The reported transient ion signals were obtained from averaging 40 pump-probe scans taken over three days.

\subsection{Theory}

Our density functional theory (DFT) calculations were conducted using Gaussian 16 suite of programs. ${ }^{46}$ The $6-311+\mathrm{G}^{*}$ (5s4p1d) basis set ${ }^{47}$ was initially used for all atoms, and subsequent calculations with the the larger CBSB7 basis set ${ }^{48}$ were performed to evaluate the energies. The total energy threshold was $10^{-8}$ a.u. from the convergence threshold that was set to $10^{-3} \mathrm{eV} / \AA$.

We used the BPW91 ${ }^{49}$ functional for preliminary geometry and ground-state energy calculations, which is in the generalized gradient approximation (GGA) family. After these preliminary calculations, neutral and cation geometries were optimized with the hybrid functionals B3LYP,${ }^{50,51}$ CAM-B3LYP,${ }^{52}$ and $\omega \mathrm{B} 97 \mathrm{XD},{ }^{53}$ along with the Møller-Plesset perturbation theory method truncated at second order (MP2). ${ }^{54}$ The calculated neutral and cation energies, along with comparison to the literature at the CBS-QB3 level and VUV photoionization experiments ${ }^{21}$ are given in Table 1. It is notable that the dispersion-corrected metaGGA exchange functionals $\omega$ B97XD and CAM-B3LYP predict vertical ionization potentials 
that agree to within $0.05 \mathrm{eV}$ with the recently reported experimental value of $9.43 \mathrm{eV} .{ }^{21}$ The neutral, cation, and aci-tautomer geometries are given in the Supporting Information, Figure S3 and Tables S1 and S2. The harmonic vibrational frequencies obtained from these calculations are tabulated in the Supporting Information, Tables S3-S5.

Table 1: Calculated energies of 2-NT and comparison to literature. $a$ Ref. $^{21}$

\begin{tabular}{llll}
\hline method & neutral (Hartree) & cation (Hartree) & $\mathrm{IP}_{\text {vert }}(\mathrm{eV})$ \\
\hline BPW91 & -476.011304 & -475.677837 & 9.074 \\
B3LYP & -476.046909 & -475.703077 & 9.356 \\
CAM-B3LYP & -475.814173 & -475.465865 & 9.478 \\
$\omega$ B97XD & -475.878995 & -475.531522 & 9.455 \\
MP2 & -474.688852 & -474.329081 & 9.790 \\
CBS-QB3 $^{a}$ & -475.311340 & -474.959199 & 9.582 \\
Expt. $^{a}$ & & & 9.43 \\
\hline
\end{tabular}

To determine the excited-state energies of the 2-NT neutral and cation, we performed time-dependent DFT (TDDFT) calculations ${ }^{55}$ to obtain the simulated optical spectrum of each species. We calculated the first 100 singlet-singlet (for neutral 2-NT) and doubletdoublet (for 2-NT cation) transitions with four different functionals: BPW91, B3LYP, CAMB3LYP and $\omega$ B97XD. Tabulated results for lowest 12 neutral 2-NT energies and 23 lowest cation energies, along with oscillator strengths, are given in the Supporting Information, Tables S6-S7. The simulated spectra for neutral 2-NT superimposed on the experimental spectrum obtained from NIST $^{56}$ are shown in Figure 2(a). As with the predicted IP $_{\text {vert }}$ values, the predicted excited state energies computed with the $\omega$ B97XD and CAM-B3LYP functionals agree very well with one another and capture the strong absorption feature centered around $4.9 \mathrm{eV}$ in the experimental spectrum. The excitation energies and oscillator strengths for the 2-NT cation shown in Figure 2(b) suggest that the lowest-lying accessible excited state lies at approximately $1.8-1.9 \mathrm{eV}$ and that the next state lies at approximately 3.2-3.4 eV. Based on these results, the probe wavelength was set at $650 \mathrm{~nm}(1.9 \mathrm{eV})$ for the experiments. The experimental probe spectrum is shown as the orange shaded region in Figure 2(b). This probe spectrum and the associated $1300 \mathrm{~nm}$ pump wavelength were used 
for all experimental measurements presented below.
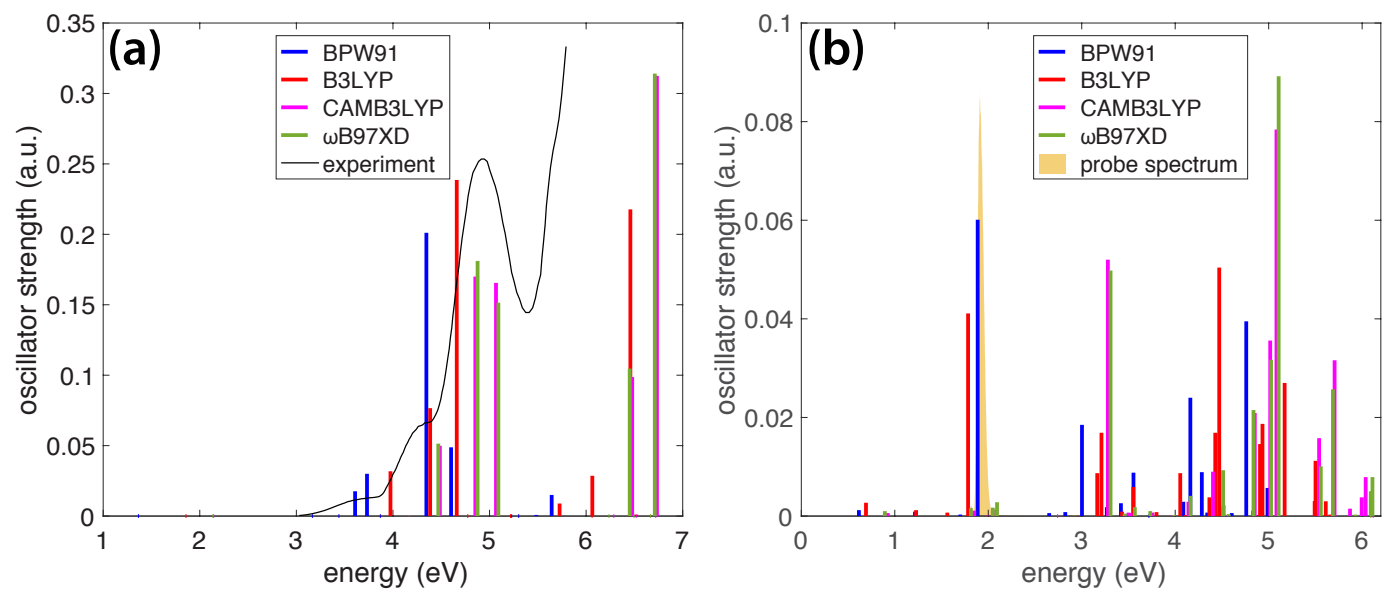

Figure 2: (a) TDDFT spectra for neutral 2-NT. Experimental spectrum obtained from NIST. ${ }^{56}$ (b) TDDFT spectra for 2-NT cation. The probe spectrum is shown as the orange shaded region. Spectra were computed using the BPW91 (blue), B3LYP (red), CAMB3LYP (magenta), and $\omega \mathrm{B} 97 \mathrm{XD}$ (green) functionals with the $6-311+\mathrm{G}^{*}$ basis.

The transition states of the hydrogen transfer in aci-rearrangement were prepared via displacements of the hydrogen atoms. The transition states of rotations and bond-breaking were scanned for using a Modredundant scan in Gaussian 16. The geometries found at the energetic cusps were then optimized using the Berny Algorithm. Using vibrational frequency calculations, these states were confirmed to correlate to first order saddle points because each transition state had one imaginary frequency with the imaginary mode vectors. To confirm the validity of the transition states found, synchronous transit-guided quasi-Newton $(\mathrm{STQN})^{57}$ calculations were performed with and without initial guesses (QST3 and QST2 respectively). To ensure that no transition state was missed, we used the transition state already found as the starting or ending point for the QST calculations. The proposed pathways were then justified using full internal reaction coordinate (IRC) ${ }^{58}$ pathways. Energies for the reaction pathways using the $\omega \mathrm{B} 97 \mathrm{XD} / \mathrm{CBSB} 7$ combination of exchange functional and basis sets are reported. Lastly, 100 ab initio molecular dynamics runs using the ADMP method ${ }^{59}$ with 0.1 fs time-steps and 280 fs duration were performed to determine the time required for the aci-rearrangement. In ADMP calculations, the forces between atoms are 
calculated via DFT (in our computations using the BPW91 functional) while the velocities are propagated classically. These simulations were initiated from the transition state for the H-atom attack and included all post ionization relaxation energy (differences in vertical and adiabatic energies of $0.1951 \mathrm{eV}$ ) in the imaginary mode.

\section{Results and Discussion}

The experiments and calculations presented here demonstrate the surprising result that vibrational coherence in 2-NT cation is preserved after it undergoes spontaneous H-atom attack to form the aci-nitro tautomer. This finding is the first (to the best of our knowledge) report of preserved vibrational coherence following an intramolecular rearrangement reaction in a radical cation, and builds on recent reports of preserved vibrational coherence in the radical cations of azobenzene ${ }^{38}$ and $N$-methyl morpholine ${ }^{60,61}$ following internal conversion. The determination of vibrational coherence preservation rests on the experimental and theoretical results presented in this section, which paint a complex picture of both coherent and incoherent excitation pathways leading to the dissociation of the 2-NT cation.

This section is organized as follows: First, we present the pump-probe mass spectrometry results (3.1), followed by a detailed analysis of the observed oscillatory ion-yield dynamics (3.2). Next, we present the computed reaction pathways leading to the formation of $\mathrm{C}_{7} \mathrm{H}_{7}{ }^{+}$, $\mathrm{C}_{7} \mathrm{H}_{6} \mathrm{NO}^{+}$, and $\mathrm{C}_{6} \mathrm{H}_{6} \mathrm{~N}^{+}$(3.3). We then discuss the experimental and theoretical evidence for coherent vibrational motions of the aci-nitro tautomer (3.4). Finally, we present a full picture of the coherent and incoherent dissociation pathways in $2-\mathrm{NT}^{+}(3.5)$.

\subsection{Pump-probe measurements}

Figure 3(a) shows the mass spectra of 2-NT taken with $1300 \mathrm{~nm}, 18 \mathrm{fs}, 2 \times 10^{14} \mathrm{~W} \mathrm{~cm}^{-2}$ pump

pulses and $650 \mathrm{~nm}, 25 \mathrm{fs}, 5 \times 10^{12} \mathrm{~W} \mathrm{~cm}^{-2}$ probe pulses at pump-probe delays $\tau=-500$ fs (bottom) and $\tau=+4000$ fs (middle), as well as their difference (top). At negative 
delay, the largest peaks in the mass spectrum are the parent 2 -NT cation at $\mathrm{m} / \mathrm{z}=137$ (highlighted in red) and the $\mathrm{OH}$ loss product $\mathrm{C}_{7} \mathrm{H}_{6} \mathrm{NO}^{+}$at $\mathrm{m} / \mathrm{z}=120$ (magenta). Because the probe is non-ionizing, the ion signal is exclusively due to the $1300 \mathrm{~nm}$ pump pulse. The large yield of parent $2-\mathrm{NT}^{+}$as compared to previously reported mass spectra taken with femtosecond lasers ${ }^{5,17,18}$ is consistent with the expected adiabatic ionization process at 1300 $\mathrm{nm}$ excitation. ${ }^{22,35,36,38-41}$ At positive delay, a decrease in the $\mathrm{m} / \mathrm{z}=137$ and $\mathrm{m} / \mathrm{z}=120$ peaks accompanied by an increase in the peaks corresponding to the smaller ions at $\mathrm{m} / \mathrm{z}=$ 92 (green), $\mathrm{m} / \mathrm{z}=91$ (blue), $\mathrm{m} / \mathrm{z}=77$ (orange), and $\mathrm{m} / \mathrm{z}=65$ (cyan) is observed. Based on previous reports, ${ }^{5,13,14,16-18,21}$ these $\mathrm{m} / \mathrm{z}$ values are assigned as to the following ions: $\mathrm{C}_{6} \mathrm{H}_{6} \mathrm{~N}^{+}$ (92), $\mathrm{C}_{7} \mathrm{H}_{7}{ }^{+}(91), \mathrm{C}_{6} \mathrm{H}_{5}{ }^{+}(77)$, and $\mathrm{C}_{5} \mathrm{H}_{5}{ }^{+}$(65). The increase in these fragment ion yields at the expense of the parent ion indicates that they are formed via excitation of the parent $2-\mathrm{NT}^{+}$by the $650 \mathrm{~nm}$ probe pulse. ${ }^{22,29-39}$
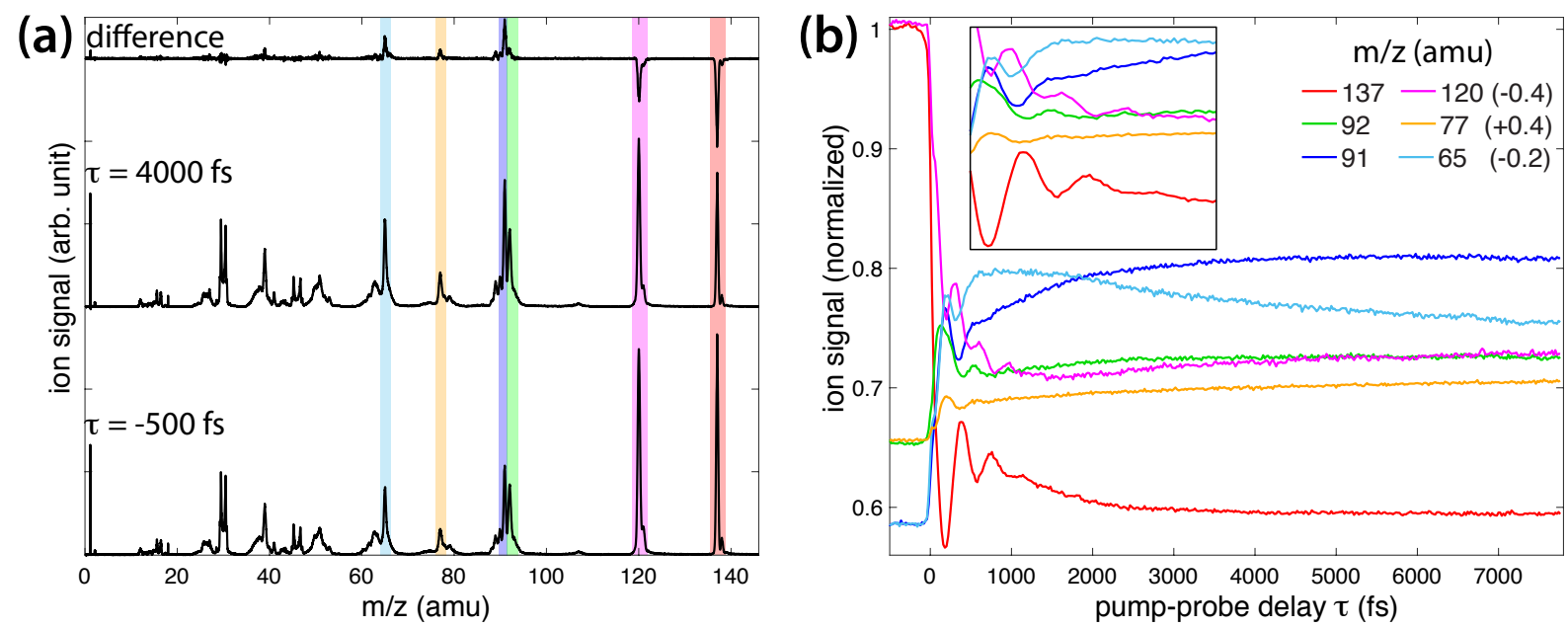

Figure 3: (a) Mass spectra of 2-NT taken at $\tau=-500$ fs and $\tau=4000$ fs, along with their difference. (b) Transient ion signals as a function of pump probe delay. The inset magnifies the region from $50-1500$ fs.

Figure 3(b) shows the transient ion signals highlighted in panel (a) as a function of pumpprobe delay $\tau$, with all signals normalized to the signal of the parent $2-\mathrm{NT}^{+}$at negative timedelay. The $\mathrm{m} / \mathrm{z}=120,77$, and 65 signals have been shifted on the ordinate axis by $-0.4,+0.4$, and -0.2 units, respectively, for clarity. The inset in Figure 3(b) magnifies the region from 
$50-1500$ fs showing the oscillating ion signals that indicate coherent vibrational dynamics. At short delay times, the oscillations in the $\mathrm{m} / \mathrm{z}=137$ and 120 ions are roughly out-of-phase with the oscillations of the smaller fragment ions, consistent with coherent excitation by the probe pulse. ${ }^{22,29-39}$ The same transient dynamics with smaller-amplitude features were observed for lower pump and probe intensities (Supporting Information, Figure S4).

\subsection{Analysis of oscillatory dynamics}

The $\sim 380$ fs oscillation period in the 2-NT ion signals is of similar magnitude to oscillation periods in the related molecules 4-NT (470 fs), ${ }^{22}$ acetophenone (650 fs), ${ }^{33,35,36}$ and 4-methylacetophenone (730 fs). ${ }^{34}$ In the latter molecules, the oscillations were attributed to the torsional motion of the nitro or acetyl substituent with respect to the benzene ring, due to the relaxation of the cation from the planar neutral geometry to the non-planar optimized geometry. ${ }^{22,33-36}$ Our $\omega$ B97XD/CBSB7 calculations indicate that the $\mathrm{C}-\mathrm{NO}_{2}$ torsional angle of $26.0^{\circ}$ in neutral $2-\mathrm{NT}$ shifts to $35.5^{\circ}$ at the optimized cation geometry (Figure 4 ), suggesting that the torsional vibrational mode can be excited upon ionization. The torsional angle for neutral 2-NT is in reasonable agreement with previous theoretical results at the PBE0/6-31 $+\mathrm{G}$ level reporting an angle of $19.4^{\circ 25}$ and within the magnitude of the estimated equilibrium torsional angle of $35 \pm 15^{\circ}$ relative to planar geometry obtained by gas-phase electron diffraction measurements. ${ }^{62}$ The calculated vibrational frequency of the torsional mode (shown in Figure 4) ranged from $45.0-65.7 \mathrm{~cm}^{-1}$ in neutral 2-NT and $31.9-57.1$ $\mathrm{cm}^{-1}$ in $2-\mathrm{NT}^{+}$, depending on the method (Supporting Information, Tables S4 - S5). The slower predicted oscillation periods of $580-1200$ fs as compared to the observed 380 fs (88 $\mathrm{cm}^{-1}$ ) can be explained by the inherent uncertainty of $\sim 30-100 \mathrm{~cm}^{-1}$ in the computed values; a similar under-estimation of the torsional frequency was found for the 4-NT cation in our previous work. ${ }^{22}$ We also note that the out-of-plane ring-bending mode calculated at $89.7-105.8 \mathrm{~cm}^{-1}$ in $2-\mathrm{NT}^{+}$is unlikely to contribute to the observed oscillations because the ring geometry remains planar upon ionization of $2-\mathrm{NT}$ to $2-\mathrm{NT}^{+}$(Figure 4). Based on these 
observations, we assign the coherent dynamics to the torsional mode.

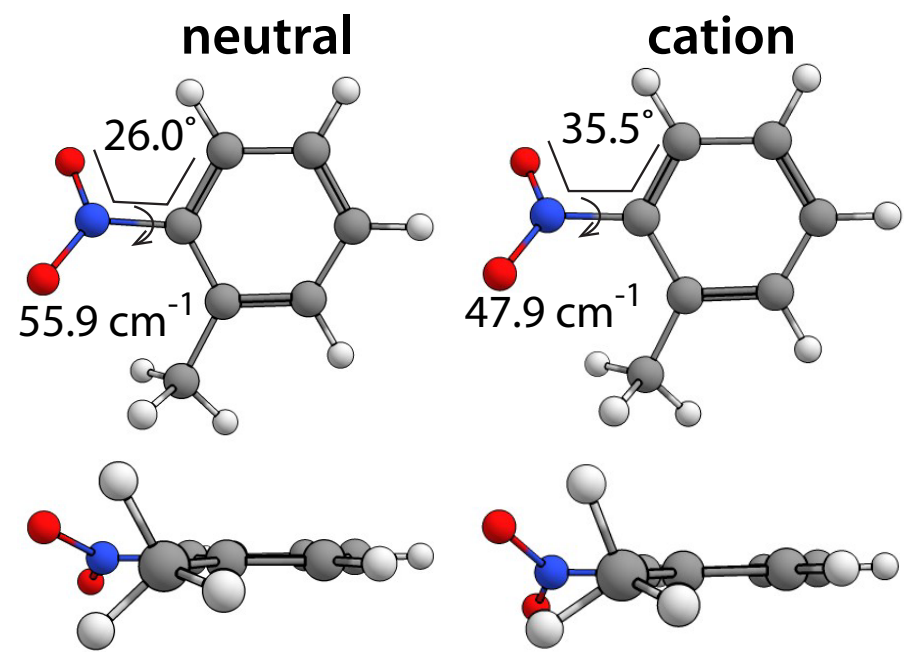

Figure 4: Neutral and ion geometries of 2-NT shown in two orientations with torsional angles and frequencies labeled.

The coherent dynamics may be analyzed in more detail by fitting the signals $S(\tau)$ for the parent 2- $\mathrm{NT}^{+}\left(\mathrm{C}_{7} \mathrm{H}_{7} \mathrm{NO}_{2}{ }^{+}\right)$and the dissociation products highlighted in Figure 3 to the equation

$$
S(\tau)=a e^{-\tau / T_{1}} \cos \left(\frac{2 \pi}{t} \tau+\phi\right)+b e^{-\tau / T_{2}}+c e^{-\tau / T_{3}}+d
$$

where $a, b$, and $c$ are amplitude coefficients, $t$ is the oscillation period, $T_{1}$ is the coherence lifetime, $T_{2}$ is a second incoherent lifetime, $T_{3}$ is a third incoherent lifetime, and $d$ is the final ion yield as $\tau \rightarrow \infty$. Each transient signal was fit to eq (1) using nonlinear least-squares curve fitting in MATLAB. Figure 5 shows the transient ion signals at $\tau>40$ fs (dots) fit to eq (1): $\mathrm{C}_{7} \mathrm{H}_{7} \mathrm{NO}_{2}{ }^{+}$(red), $\mathrm{C}_{6} \mathrm{H}_{6} \mathrm{~N}^{+}$(green), and $\mathrm{C}_{6} \mathrm{H}_{5}{ }^{+}$(orange) in Figure 5(a); $\mathrm{C}_{7} \mathrm{H}_{7}{ }^{+}$ (blue), $\mathrm{C}_{5} \mathrm{H}_{5}{ }^{+}$(cyan), and $\mathrm{C}_{7} \mathrm{H}_{6} \mathrm{NO}^{+}$(magenta) in Figure 5(b). For each transient signal, the fit components corresponding to the coherent $T_{1}$ decay (thick solid lines), $T_{2}$ decay (dashed lines), and $T_{3}$ decay (dotted lines) are shown in addition to the full fit function (black lines). The $\mathrm{C}_{7} \mathrm{H}_{7} \mathrm{NO}_{2}{ }^{+}, \mathrm{C}_{5} \mathrm{H}_{5}{ }^{+}, \mathrm{C}_{7} \mathrm{H}_{6} \mathrm{NO}^{+}$, and $\mathrm{C}_{6} \mathrm{H}_{6} \mathrm{~N}^{+}$transients required the additional $T_{3}$ decay, while the $\mathrm{C}_{7} \mathrm{H}_{7}{ }^{+}$and $\mathrm{C}_{6} \mathrm{H}_{5}{ }^{+}$transients required only two decay time constants.

The coefficients extracted from curve fitting to each transient in Figures 5(a) and 5(b) 

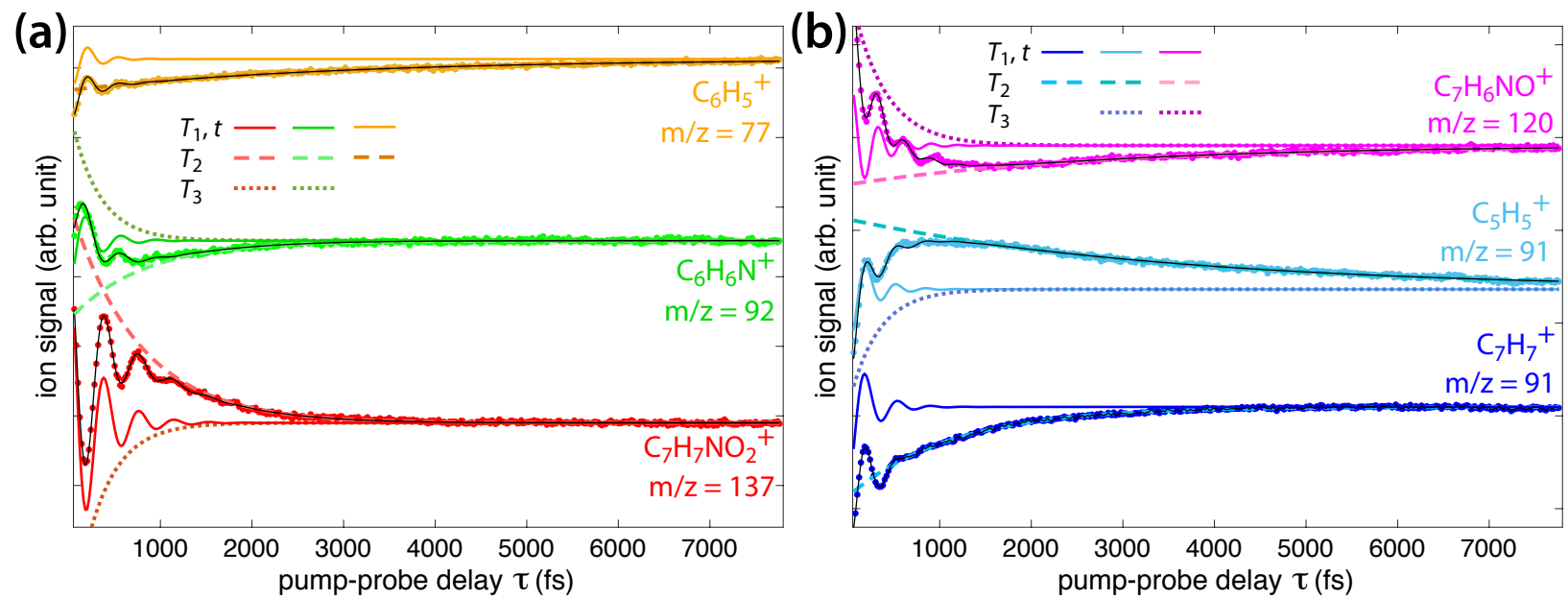

Figure 5: Transient signals (dots) of (a) $\mathrm{C}_{7} \mathrm{H}_{7} \mathrm{NO}_{2}{ }^{+}$(red), $\mathrm{C}_{6} \mathrm{H}_{6} \mathrm{~N}^{+}$(green), $\mathrm{C}_{6} \mathrm{H}_{5}$ (orange), and (b) $\mathrm{C}_{7} \mathrm{H}_{7}{ }^{+}$(blue), $\mathrm{C}_{5} \mathrm{H}_{5}$ (cyan) $\mathrm{C}_{7} \mathrm{H}_{6} \mathrm{NO}^{+}$(magenta). All transients are shown with fits to eq 1 (black lines) and individual components (thick solid, dashed, and dotted lines).

are given in Tables 2 and 3, respectively. All transient signals have coherent lifetimes $\left(T_{1}\right)$ between approximately 200 and $300 \mathrm{fs}$, similar to the lifetimes found in 3 -NT and $4-\mathrm{NT} .{ }^{22}$ In Table 2 , the oscillation periods $(t)$ are nearly identical for the parent $\mathrm{C}_{7} \mathrm{H}_{7} \mathrm{NO}_{2}{ }^{+}(382 \mathrm{fs})$ and $\mathrm{C}_{6} \mathrm{H}_{6} \mathrm{~N}^{+}$transients (386 fs), and their phases are roughly $\pi$ radians out-of-phase. In contrast, Table 3 shows a significantly shorter period of 290 fs for $\mathrm{C}_{7} \mathrm{H}_{6} \mathrm{NO}^{+}$, and its phase is offset from that of the $\mathrm{C}_{7} \mathrm{H}_{7} \mathrm{NO}_{2}{ }^{+}$transient by $\pi / 4$ radians. The remaining excited-state products $\mathrm{C}_{6} \mathrm{H}_{5}{ }^{+}, \mathrm{C}_{5} \mathrm{H}_{5}{ }^{+}$, and $\mathrm{C}_{7} \mathrm{H}_{7}{ }^{+}$exhibit oscillation periods and phases in between these two extremes. Also of note are the similar $T_{3}$ values in $\mathrm{C}_{7} \mathrm{H}_{7} \mathrm{NO}_{2}{ }^{+}, \mathrm{C}_{7} \mathrm{H}_{6} \mathrm{NO}^{+}, \mathrm{C}_{6} \mathrm{H}_{6} \mathrm{~N}^{+}$, and $\mathrm{C}_{5} \mathrm{H}_{5}{ }^{+}$, indicating an incoherent excitation process linking these four transients.

Table 2: Coefficients extracted from fitting transient ion signals in Figure 5(a) to eq (1).

\begin{tabular}{lccc}
\hline eq (1) & $\mathrm{C}_{7} \mathrm{H}_{7} \mathrm{NO}_{2}{ }^{+}$ & $\mathrm{C}_{6} \mathrm{H}_{6} \mathrm{~N}^{+}$ & $\mathrm{C}_{6} \mathrm{H}_{5}{ }^{+}$ \\
\hline$a$ & $0.124 \pm 0.003$ & $0.037 \pm 0.004$ & $0.025 \pm 0.003$ \\
$T_{1}(\mathrm{fs})$ & $288 \pm 7$ & $244 \pm 36$ & $188 \pm 19$ \\
$t(\mathrm{fs})$ & $382 \pm 2$ & $386 \pm 13$ & $338 \pm 13$ \\
$\phi(\mathrm{rad})$ & $-0.17 \pm 0.03$ & $3.12 \pm 0.16$ & $2.23 \pm 0.14$ \\
$b$ & $0.149 \pm 0.029$ & $-0.066 \pm 0.031$ & $-0.0225 \pm 0.0005$ \\
$T_{2}(\mathrm{fs})$ & $760 \pm 40$ & $720 \pm 120$ & $2930 \pm 150$ \\
$c$ & $-0.15 \pm 0.02$ & $0.10 \pm 0.03$ & - \\
$T_{3}(\mathrm{fs})$ & $317 \pm 31$ & $322 \pm 63$ & - \\
$d$ & $0.594 \pm 0.001$ & $0.725 \pm 0.001$ & $0.296 \pm 0.001$ \\
\hline
\end{tabular}


Table 3: Coefficients extracted from fitting transient ion signals in Figure 5(b) to eq (1).

\begin{tabular}{lccc}
\hline eq (1) & $\mathrm{C}_{7} \mathrm{H}_{6} \mathrm{NO}^{+}$ & $\mathrm{C}_{5} \mathrm{H}_{5}{ }^{+}$ & $\mathrm{C}_{7} \mathrm{H}_{7}{ }^{+}$ \\
\hline$a$ & $0.072 \pm 0.004$ & $0.065 \pm 0.006$ & $0.087 \pm 0.005$ \\
$T_{1}(\mathrm{fs})$ & $260 \pm 17$ & $212 \pm 20$ & $210 \pm 11$ \\
$t(\mathrm{fs})$ & $291 \pm 3$ & $330 \pm 10$ & $361 \pm 5$ \\
$\phi(\mathrm{rad})$ & $-0.95 \pm 0.08$ & $2.45 \pm 0.17$ & $2.91 \pm 0.15$ \\
$b$ & $-0.040 \pm 0.002$ & $0.076 \pm 0.002$ & $-0.096 \pm 0.001$ \\
$T_{2}(\mathrm{fs})$ & $2890 \pm 480$ & $3580 \pm 280$ & $1100 \pm 20$ \\
$c$ & $0.174 \pm 0.003$ & $-0.127 \pm 0.004$ & - \\
$T_{3}(\mathrm{fs})$ & $359 \pm 14$ & $319 \pm 19$ & - \\
$d$ & $1.131 \pm 0.001$ & $0.937 \pm 0.001$ & $0.809 \pm 0.001$ \\
\hline
\end{tabular}

To assess the potential significance of the distinct oscillation periods across the transient ions extracted from curve-fitting, the $T_{2}$ and $T_{3}$ components of eq 1 were subtracted off from each transient ion signal and the residuals plotted in Figure 6(a). The dashed lines at 190 fs, $570 \mathrm{fs}$, and $950 \mathrm{fs}$ indicate minima in the yield of $\mathrm{C}_{7} \mathrm{H}_{7} \mathrm{NO}_{2}{ }^{+}$(red), showing a constant period of 380 fs. Both the $\mathrm{C}_{6} \mathrm{H}_{6} \mathrm{~N}^{+}$(green) and $\mathrm{C}_{6} \mathrm{H}_{5}{ }^{+}$(orange) transients exhibit almost perfectly antiphase oscillations with the parent ion, indicating their formation from its coherent excitation. The $\mathrm{C}_{7} \mathrm{H}_{7}^{+}$transient (blue) oscillations are also almost antiphase with the $\mathrm{C}_{7} \mathrm{H}_{7} \mathrm{NO}_{2}{ }^{+}$, although the first $\mathrm{C}_{7} \mathrm{H}_{7}{ }^{+}$minimum at $370 \mathrm{fs}$ is approximately 10 fs ahead of the first $\mathrm{C}_{7} \mathrm{H}_{7} \mathrm{NO}_{2}{ }^{+}$maximum at $380 \mathrm{fs}$. The dotted lines at $180 \mathrm{fs}, 470 \mathrm{fs}$, and $780 \mathrm{fs}$ indicate minima in the $\mathrm{C}_{7} \mathrm{H}_{6} \mathrm{NO}^{+}$yield, indicating that the oscillation period increases from 290 fs between the first and second minima to 310 fs between the second and third minima. These distinct oscillatory dynamics indicate that a different structure gives rise to the $\mathrm{C}_{7} \mathrm{H}_{6} \mathrm{NO}^{+}$oscillations as compared to the parent $\mathrm{C}_{7} \mathrm{H}_{7} \mathrm{NO}_{2}{ }^{+}$oscillations. The $\mathrm{C}_{5} \mathrm{H}_{5}{ }^{+}$signal (cyan) exhibits oscillations that are not perfectly out-of-phase with either the $\mathrm{C}_{7} \mathrm{H}_{7} \mathrm{NO}_{2}{ }^{+}$or $\mathrm{C}_{7} \mathrm{H}_{6} \mathrm{NO}^{+}$transients: its first minimum at $340 \mathrm{fs}$ is $40 \mathrm{fs}$ ahead of the $\mathrm{C}_{7} \mathrm{H}_{7} \mathrm{NO}_{2}{ }^{+}$maximum and $20 \mathrm{fs}$ behind the first $\mathrm{C}_{7} \mathrm{H}_{6} \mathrm{NO}^{+}$maximum at 320 fs. These results suggest that $\mathrm{C}_{5} \mathrm{H}_{5}{ }^{+}$ can be formed by excitation of both the $\mathrm{C}_{7} \mathrm{H}_{7} \mathrm{NO}_{2}{ }^{+}$and $\mathrm{C}_{7} \mathrm{H}_{6} \mathrm{NO}^{+}$precursor structures.

Fast Fourier Transform (FFT) of the oscillatory signals from 60 - 3000 fs in Figure 6(a) are shown in Figure 6(b). The well-resolved peak in the $\mathrm{C}_{7} \mathrm{H}_{7} \mathrm{NO}_{2}{ }^{+}$signal (red) at $91 \mathrm{~cm}^{-1}$ 

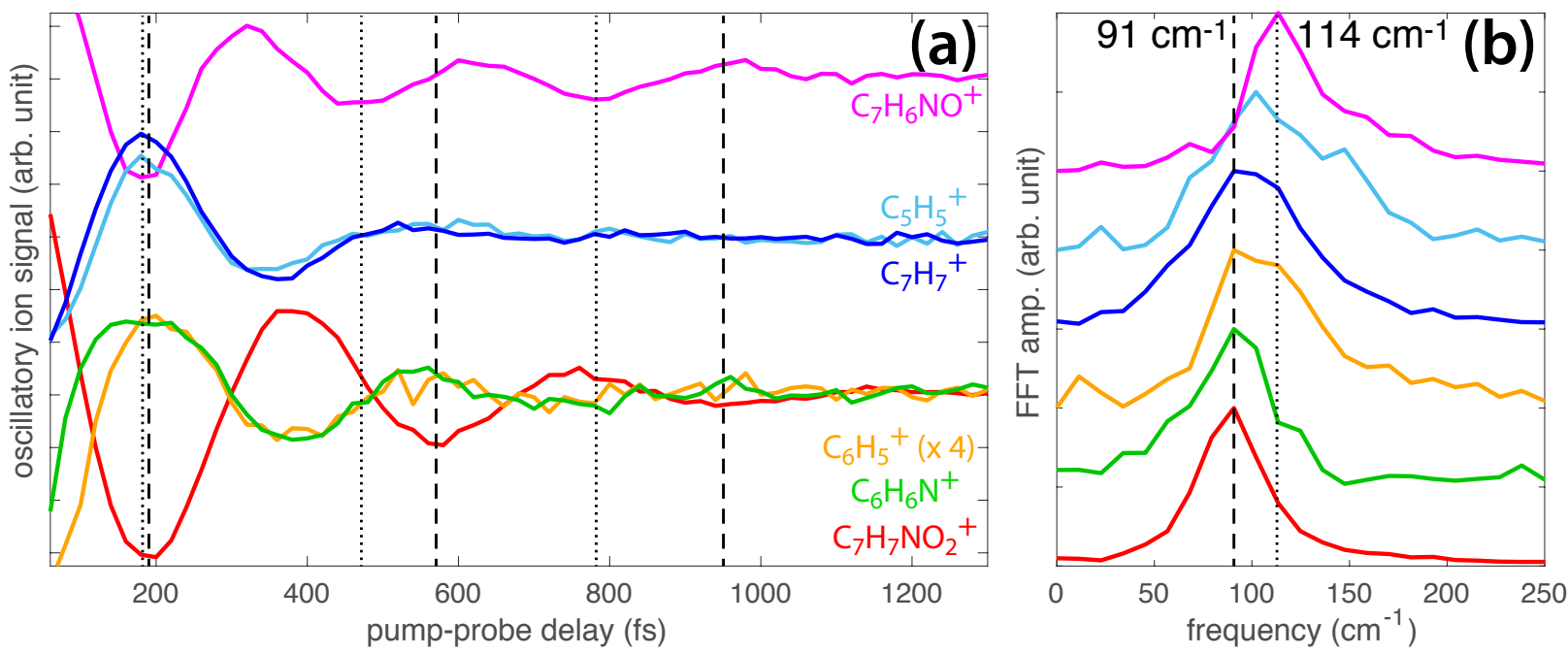

Figure 6: (a) Oscillatory components of the transient ion signals of $\mathrm{C}_{7} \mathrm{H}_{7} \mathrm{NO}_{2}{ }^{+}$(red), $\mathrm{C}_{6} \mathrm{H}_{6} \mathrm{~N}^{+}$ (green), $\mathrm{C}_{7} \mathrm{H}_{7}^{+}$(blue), and $\mathrm{C}_{7} \mathrm{H}_{6} \mathrm{NO}^{+}$(magenta). Dashed and dotted lines denote minima in $\mathrm{C}_{7} \mathrm{H}_{7} \mathrm{NO}_{2}{ }^{+}$and $\mathrm{C}_{7} \mathrm{H}_{6} \mathrm{NO}^{+}$, respectively. (b) FFT of signals in (a).

(367 fs period) indicated by the dashed line agrees with the 383 fs oscillation period obtained from fitting to eq (1). The $\mathrm{C}_{6} \mathrm{H}_{6} \mathrm{~N}^{+}$(green), $\mathrm{C}_{6} \mathrm{H}_{5}^{+}$(orange), and $\mathrm{C}_{7} \mathrm{H}_{7}^{+}$(blue) signals also show this peak, although the peaks are somewhat broadened in $\mathrm{C}_{6} \mathrm{H}_{5}^{+}$and $\mathrm{C}_{7} \mathrm{H}_{7}^{+}$. In contrast, the $\mathrm{C}_{7} \mathrm{H}_{6} \mathrm{NO}^{+}$peak (magenta) is clearly up-shifted to $114 \mathrm{~cm}^{-1}$ (293 fs period) indicated by the dotted line, with a long tail extending to the higher frequencies. The asymmetrical peak is consistent with the slowing oscillation period observed in Figure 6(a). The distinctly higher frequency for $\mathrm{C}_{7} \mathrm{H}_{6} \mathrm{NO}^{+}$provides further evidence that the structure giving rise to these oscillations is distinct from the parent $2 \mathrm{NT}^{+}$. The $\mathrm{C}_{5} \mathrm{H}_{5}{ }^{+}$(cyan) peak is also up-shifted from the $\mathrm{C}_{7} \mathrm{H}_{7} \mathrm{NO}_{2}{ }^{+}$frequency, providing further evidence that it can be formed from both the parent $2 \mathrm{NT}^{+}$and the $\mathrm{C}_{7} \mathrm{H}_{6} \mathrm{NO}^{+}$precursor structure. In order to rationalize the observation of two distinct coherently excited structures in our pump-probe data, we present results of computed reaction pathways in $2-\mathrm{NT}^{+}$in Section 3.3 and then propose that the oscillations in the $\mathrm{C}_{7} \mathrm{H}_{6} \mathrm{NO}^{+}$yield may be attributed to coherent motion and relaxation of the aci-nitro tautomer of $2-\mathrm{NT}^{+}$in Section 3.4. 


\subsection{Computed reaction pathways in $2-\mathrm{NT}^{+}$}

We now consider the reaction pathways that lead to the formation of the $2-\mathrm{NT}^{+}$fragmentation products $\mathrm{C}_{7} \mathrm{H}_{7}{ }^{+}, \mathrm{C}_{7} \mathrm{H}_{6} \mathrm{NO}^{+}$, and $\mathrm{C}_{6} \mathrm{H}_{6} \mathrm{~N}^{+}$. All computational results were performed with the $\omega$ B97XD/CBSB7 method.

\subsubsection{Direct $\mathrm{C}-\mathrm{NO}_{2}$ bond homolysis: Formation of $\mathrm{C}_{7} \mathrm{H}_{7}^{+}$}

The similar oscillation periods and offset phases of the $\mathrm{C}_{7} \mathrm{H}_{7} \mathrm{NO}_{2}{ }^{+}$and $\mathrm{C}_{7} \mathrm{H}_{7}{ }^{+}$transients (Tables 2, 3 and Figure 6) suggest that coherent excitation of the parent molecular ion results in $\mathrm{C}-\mathrm{NO}_{2}$ homolysis to form $\mathrm{C}_{7} \mathrm{H}_{7}{ }^{+}$, as was observed in 3-NT and 4-NT. ${ }^{22}$ Computation of this dissociation pathway revealed no transition state and formation of $\mathrm{C}_{7} \mathrm{H}_{7}{ }^{+}$in the singlet and triplet states at $10.98 \mathrm{eV}$ and $11.69 \mathrm{eV}$, respectively (Figure 7). The singlet dissociation energy is in good agreement with recent VUV photoionization experiments giving an appearance energy for $\mathrm{C}_{7} \mathrm{H}_{7}{ }^{+}$at $11.01 \pm 0.03 \mathrm{eV}$ and calculations at the CBS-QB3 level indicating dissociation at $11.17 \mathrm{eV} .{ }^{21}$ The $1.9 \mathrm{eV}$ probe pulse (orange arrow, Figure 7) can easily exceed the dissociation barrier to singlet $\mathrm{C}_{7} \mathrm{H}_{7}{ }^{+}$formation but doesn't exceed the barrier for triplet formation, suggesting that the observed $\mathrm{C}_{7} \mathrm{H}_{7}{ }^{+}$is formed exclusively in the singlet state.

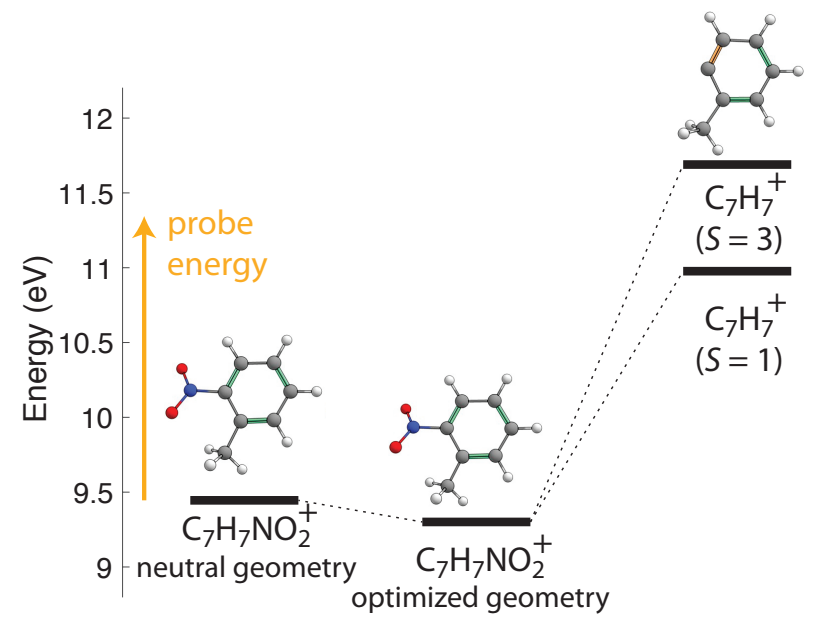

Figure 7: Mechanism of $-\mathrm{NO}_{2}$ loss from $2-\mathrm{NT}^{+}$showing the energy required to form $\mathrm{C}_{7} \mathrm{H}_{7}{ }^{+}$ in both singlet $(S=1)$ and triplet $(S=3)$ states. The probe photon energy is shown to scale (orange arrow). 


\subsubsection{H-atom attack and $\mathrm{OH}$ loss: Formation of $\mathrm{C}_{7} \mathrm{H}_{6} \mathrm{NO}^{+}$}

The high yield of $\mathrm{C}_{7} \mathrm{H}_{6} \mathrm{NO}^{+}$in our mass spectra at negative time-delay (i.e., in the absence of the probe pulse) indicates that the parent $2 \mathrm{NT}^{+}$can spontaneously undergo acirearrangement via $\mathrm{H}$-atom attack and lose $\mathrm{OH}$ on the $\sim \mu$ s flight time in the TOF-MS, consistent with previous mass spectrometry studies. ${ }^{5,13,14,16-18,21}$ According to our computations of the aci-rearrangement reaction pathway (Figure 8), the reaction has an activation barrier of $0.76 \mathrm{eV}$ from the vertical IP of $9.45 \mathrm{eV}$. This energy is lower than the pump photon energy $(0.95 \mathrm{eV}$ at $1300 \mathrm{~nm})$, which suggests that absorption of an additional pump photon during the ionization process can provide the necessary energy to initiate the H-atom attack. Once TS1 is reached and the hydrogen transfers to the nitro oxygen (INT1 in Figure 8), a series of rotations (TSr, Int1r, and TSr2 in Figure 8) result in the most stable aci-nitro tautomer INT2 at $8.62 \mathrm{eV}$.
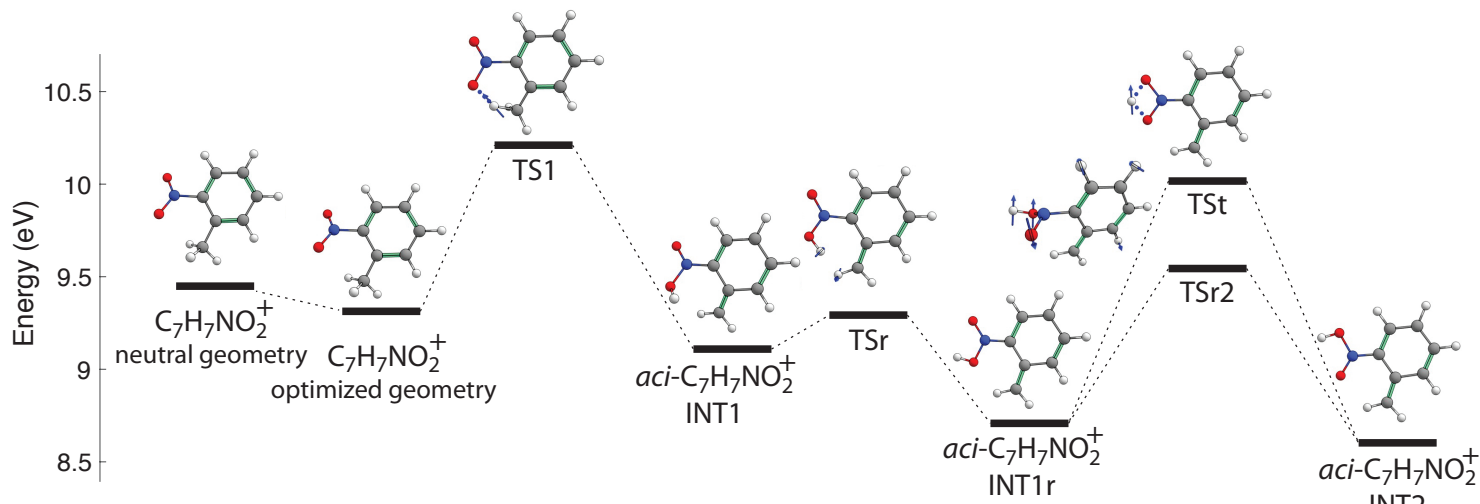

INT2

Figure 8: Mechanism of aci-rearrangement in $2 \mathrm{NT}^{+}$computed at the $\omega$ B97XD/CBSB7 level.

This mechanism generally agrees with the recently reported pathway computed at the CBS-QB3 level with the $6-311 \mathrm{G}$ basis ${ }^{21}$ with three notable exceptions. First, the $10.22 \mathrm{eV}$ energy of the transition state TS1 is $0.2 \mathrm{eV}$ higher than the CBS-QB3 value. Second, the final transition state TSr2 was not reported in the CBS-QB3 results, but rather the transition state TSt, which was reported to be the highest-energy transition state in the pathway at $10.16 \mathrm{eV}$ (compared to $10.01 \mathrm{eV}$ in our calculations). Third, the aci-nitro tautomer INT2 
was reported to be $0.38 \mathrm{eV}$ higher at $9.00 \mathrm{eV}$. These discrepancies are likely due to the use of a composite method to compute energies with DFT-optimized geometries in Ref., ${ }^{21}$ in contrast to the use of a consistent DFT method to optimize both the geometries and energies in the present calculations. Furthermore, all transition states in our computations were verified with IRC pathway calculations. The corresponding structures (Supporting Information, Figure S5) clearly show the displacement vectors in each transition state.

To estimate the time needed for $\mathrm{H}$ atom transfer to the nitro oxygen, ADMP trajectories were computed beginning from TS1 with the excess energy of $0.195 \mathrm{eV}$ from cation relaxation. The zero point vibrational energy (ZPVE) was also included and partitioned among the non-imaginary vibrational modes using microcanonical sampling. Hydrogen transfer was measured using the bond radii $\mathrm{R}(11-14)(\mathrm{C}-\mathrm{H})$ and $\mathrm{R}(14-17)(\mathrm{O}-\mathrm{H})$ (Figure 9). The average times required to reach TS1 and INT1 from the optimized 2-NT+ $\mathrm{NT}^{+}$geometry obtained by these calculations (Figure 9) indicate that the INT1 aci-nitro tautomer structure can be accessed as soon as $20.8 \pm 5.9$ fs. The average trajectories for the forward (from TS1 to INT1) and reverse (from TS1 to $2 \mathrm{NT}^{+}$) hydrogen motions leading to the computed reaction times are given in the Supporting Information, Figure S6. Continued simulation of the forward reaction out to 500 fs found that the average time required to access the next transition state TSr is $145 \pm 75$ fs. Because the ADMP trajectories were initiated from TS1, the computed 21 fs timescale likely represents a lower limit on the reaction time. A more reasonable timescale is on the order of $\sim 60$ fs, which was observed for intramolecular H-atom attack reactions in excited-state methyl salicylate ${ }^{63}$ and 2-(2'-hydroxyphenyl)benzothiazole. ${ }^{64}$ The excitedstate dynamics leading to such rapid H-atom attack in the latter works also suggests that the reaction in 2-NT cation may occur on an excited state PES, although future computational studies will be needed to test this hypothesis. Nevertheless, the calculations suggest that some population of aci-nitro tautomer as structure INT1 is likely present by the time the coherent oscillations are observable beginning at 100 fs (c.f., Figure 6), while the structure's relaxation to the stable structure INT2 is expected to proceed over the next several hundred 
femtoseconds. As will be discussed below in Section 3.4, both the H-atom transfer and relaxation timescales are consistent with the observed oscillations in the $\mathrm{C}_{7} \mathrm{H}_{6} \mathrm{NO}^{+}$transient arising from coherent torsional motion of the aci-nitro tautomer.
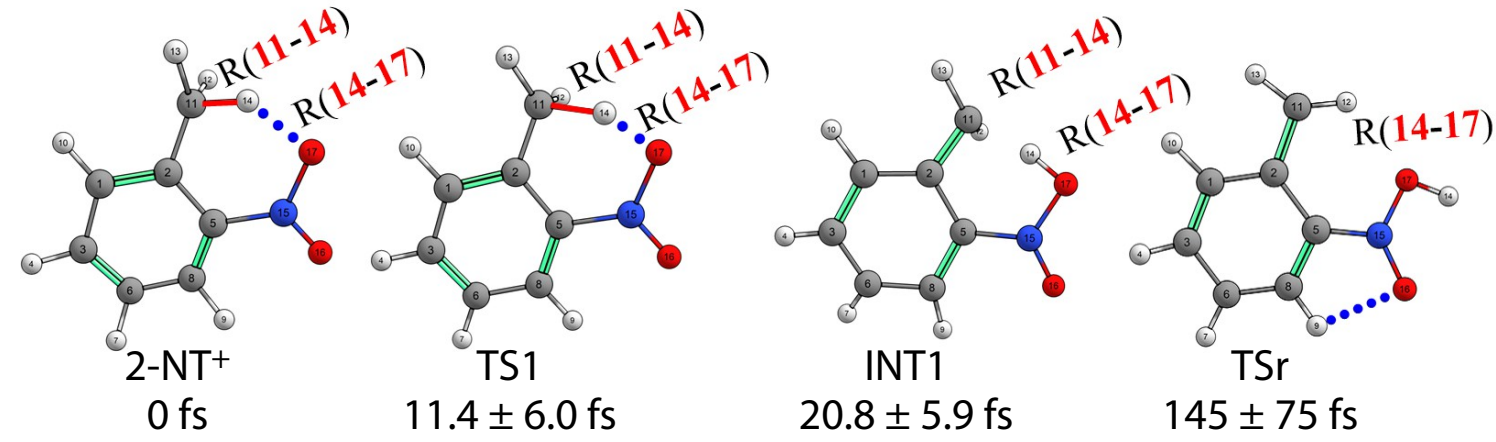

Figure 9: Structures involved in the $\mathrm{H}$ atom transfer to the nitro oxygen, along with average times required to reach them.

We next consider pathways to $\mathrm{OH}$ loss and formation of $\mathrm{C}_{7} \mathrm{H}_{6} \mathrm{NO}^{+}$beginning from INT2 (Figure 10 and Supporting Information, Figure S7). The most favorable pathway leads to $\mathrm{C}_{7} \mathrm{H}_{6} \mathrm{NO}^{+}$in the singlet state, and involves first cyclization (TS2 and INT3) followed by OH cleavage to produce $\mathrm{C}_{7} \mathrm{H}_{6} \mathrm{NO}^{+}(\mathrm{P} 2, S=1$, Figure 10). Because the energy of P2 $(9.63 \mathrm{eV}$, in good agreement with the $9.65 \mathrm{eV}$ reported with CBS-QB3 calculations ${ }^{21}$ ) is lower than the TS1 energy required to initiate aci-rearrangement, this pathway requires no additional input energy and we can assume that any spontaneously-formed aci-nitro tautomer will lose $\mathrm{OH}$ before reaching the ion detector in our experiments. This result explains the high yield of $\mathrm{C}_{7} \mathrm{H}_{6} \mathrm{NO}^{+}$at negative time-delays in our experiments, which we assign to the $S=1 \mathrm{P} 2$ product.

In addition to the spontaneous P2 formation pathway, Figure 10 also indicates three higher-energy pathways leading to different $\mathrm{C}_{7} \mathrm{H}_{6} \mathrm{NO}^{+}$structures that become accessible upon absorption of one probe photon (orange arrows) from either the vertical IP (i.e., by the parent molecular ion $2-\mathrm{NT}^{+}$) or the aci-nitro tautomer with initial energy equal to that of TS1. Direct OH loss from INT2 can form either singlet $(S=1)$ or triplet $(S=3) \mathrm{C}_{7} \mathrm{H}_{6} \mathrm{NO}^{+}$ as structure $\mathrm{P} 1$ with energies $11.07 \mathrm{eV}$ and $10.90 \mathrm{eV}$, respectively. The $S=3$ product can 
then cyclize with an additional $1.32 \mathrm{eV}$ energy through TS2b to produce the cyclic $\mathrm{P} 2$ in the triplet state. These dissociation pathways, which are only accessible upon probe excitation, explain the presence of the $T_{3}$ timescale in the transient ion signals of the parent $2-\mathrm{NT}^{+}$and $\mathrm{C}_{7} \mathrm{H}_{6} \mathrm{NO}^{+}$, where the opposite signs of the corresponding amplitude coefficients ( $c$ in Tables 2 and 3) indicate that direct excitation of the parent ion can induce $\mathrm{OH}$ loss. As a result, the $T_{3}$ contribution to the $\mathrm{C}_{7} \mathrm{H}_{6} \mathrm{NO}^{+}$signal in our experiments is expected to arise from both the singlet state $\mathrm{P} 1$ and triplet-state $\mathrm{P} 1 / \mathrm{P} 2$ dissociation pathways.

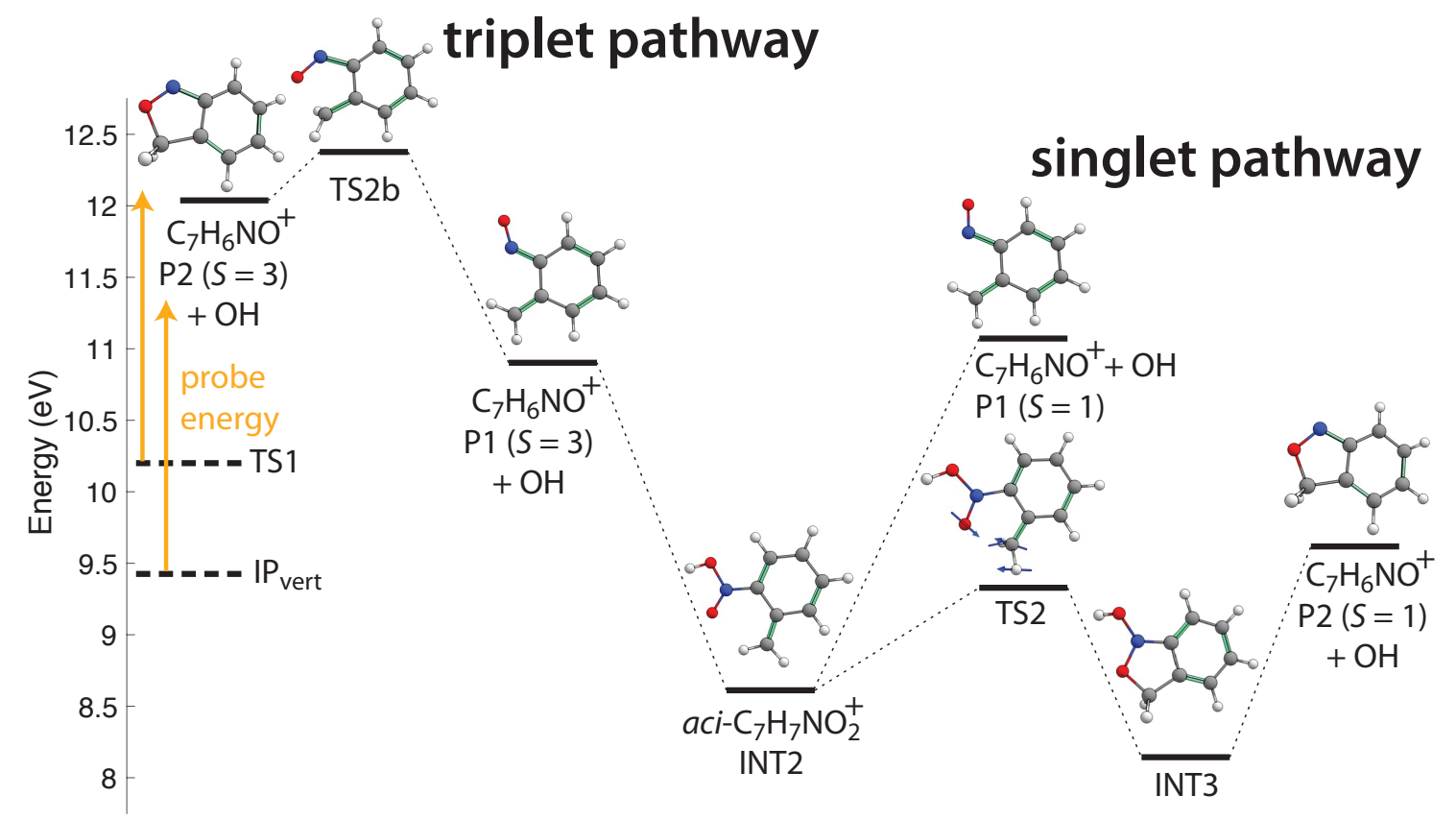

Figure 10: Mechanism of dissociation from the aci-nitro tautomer to $\mathrm{C}_{7} \mathrm{H}_{6} \mathrm{NO}^{+}$products formed in the singlet and triplet states.

\subsubsection{CO loss from $\mathrm{C}_{7} \mathrm{H}_{6} \mathrm{NO}^{+}$: Formation of $\mathrm{C}_{6} \mathrm{H}_{6} \mathrm{~N}^{+}$}

Finally, we turn to the $\mathrm{CO}$ loss pathway from $\mathrm{C}_{7} \mathrm{H}_{6} \mathrm{NO}^{+}$to form $\mathrm{C}_{6} \mathrm{H}_{6} \mathrm{~N}^{+}$. Previous theoretical studies examined $\mathrm{CO}$ loss from only the singlet $\mathrm{C}_{7} \mathrm{H}_{6} \mathrm{NO}^{+}$product (P2, Figure 10), which indicated a large $2.61 \mathrm{eV}$ dissociation barrier. ${ }^{21}$ We computed the CO loss pathways beginning from the P2 structures in both the singlet and triplet states (Figures 11(a) and (b), respectively, and Supporting Information, Figures S8 and S9). 


\section{(a) $S=1$ pathway}

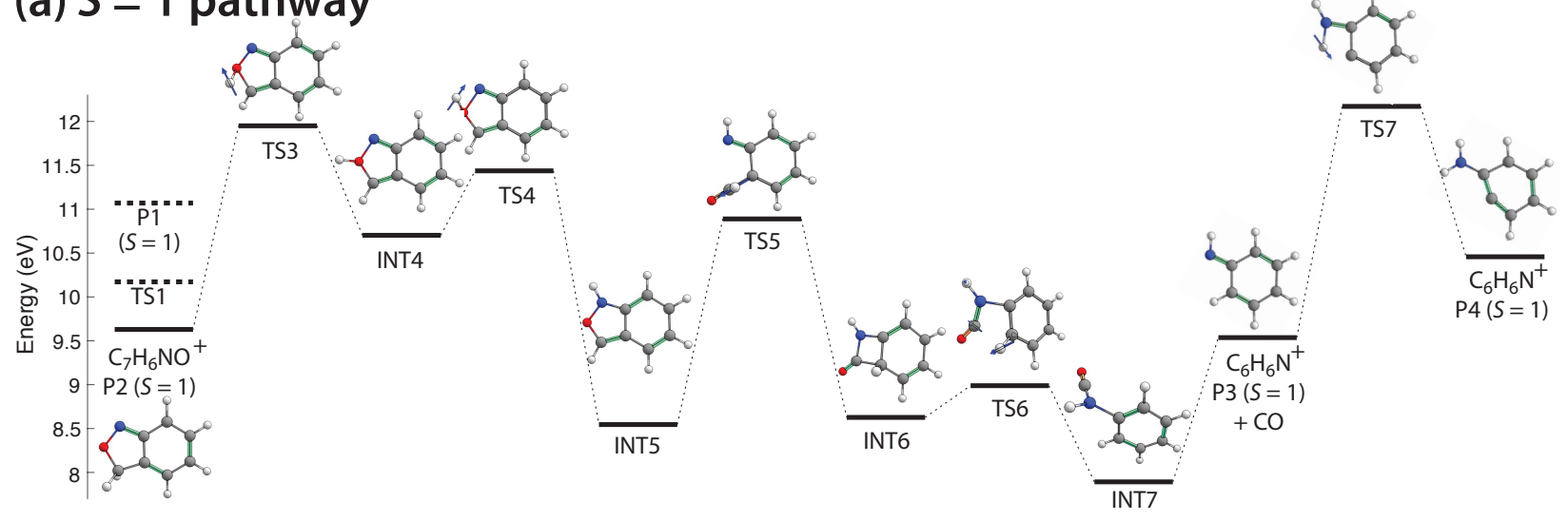

\section{(a) $S=3$ pathway}
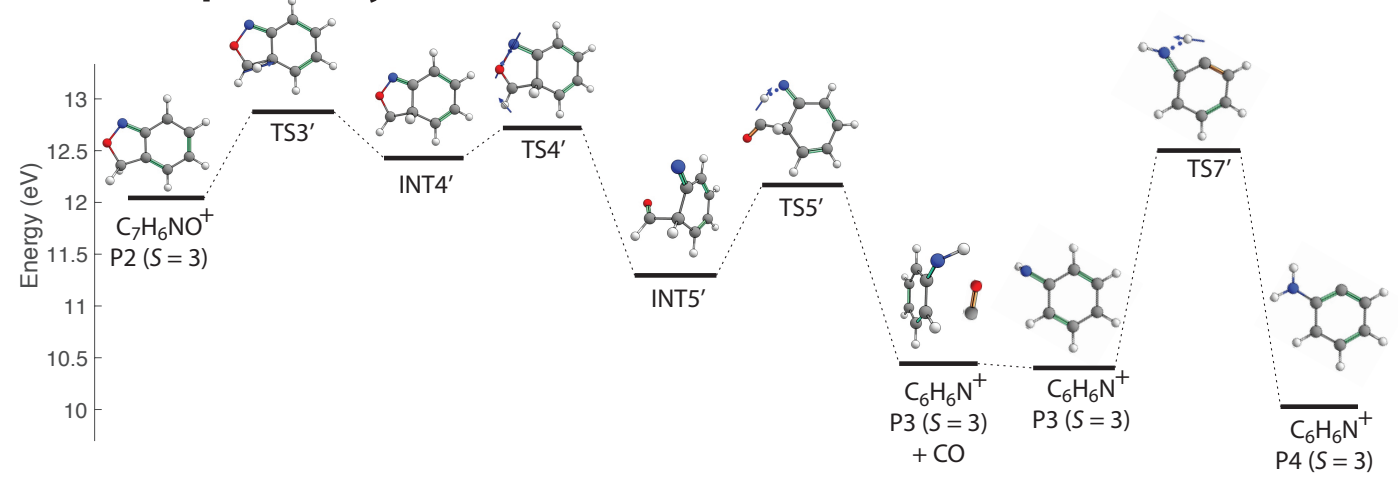

Figure 11: Mechanism of $\mathrm{CO}$ loss from $\mathrm{C}_{7} \mathrm{H}_{6} \mathrm{NO}^{+}$products $\mathrm{P} 2$ formed in (a) singlet and (b) triplet states.

In rough agreement with Ref., ${ }^{21}$ the singlet $\mathrm{C}_{7} \mathrm{H}_{6} \mathrm{NO}^{+}$requires $2.32 \mathrm{eV}$ to lose the $\mathrm{CO}$ moiety. These results indicate that the $\mathrm{C}_{7} \mathrm{H}_{6} \mathrm{NO}^{+}$formed via the lowest-energy singlet pathway in Figure 10 does not have enough energy to lose CO, even when taking into consideration the TS1 energy, as the energy barrier to reach TS3 is still $1.73 \mathrm{eV}$. In contrast, the singlet P1 that becomes accessible following absorption of a probe photon (dashed line, Figure 11(a)) only requires an extra $0.88 \mathrm{eV}$ to induce a series of hydrogen atom migrations and internal rotations that leads to $\mathrm{CO}$ loss and production of the $\mathrm{C}_{6} \mathrm{H}_{6} \mathrm{~N}^{+}$product P3 (Figure 11(a)). From the triplet P2, an additional energy input of $0.84 \mathrm{eV}$ initiates a more direct CO loss pathway to form P3 in the triplet state (Figure 11(b)). We note that an additional higher-energy triplet dissociation pathway analogous to the singlet pathway in Figure 11(a) was also identified, as shown in the Supporting Information, Figures S10 and 
S11. Collectively, these computed dissociation pathways suggest that the $\mathrm{C}_{7} \mathrm{H}_{6} \mathrm{NO}^{+}$formed in either the singlet or triplet state upon absorption of a probe photon can lose CO with little additional energy input. Therefore, both the observed $T_{3}$ relaxation timescale and oscillations in the $\mathrm{C}_{6} \mathrm{H}_{6} \mathrm{~N}^{+}$fragment can both be attributed to excitation of the parent ion by the probe pulse.

\subsection{Preservation of vibrational coherence in the aci-nitro tautomer}

The distinct oscillatory dynamics observed in the $\mathrm{C}_{7} \mathrm{H}_{6} \mathrm{NO}^{+}$ion as compared to other ions (Figure 6) suggests that its precursor is a distinct structure from the parent $2-\mathrm{NT}^{+}$. Coupled to the ADMP results in Figure 9 and previous pump-probe results on intramolecular H-atom attack in excited state neutrals, ${ }^{63,64}$ we propose that these oscillations arise from coherent vibrational dynamics in the $a c i$-nitro tautomer of $2-\mathrm{NT}^{+}$. The aci-nitro tautomer as structure INT1 is predicted to form as early as $\sim 20$ fs based on the ADMP results, and at least by $\sim 60$ fs based on earlier experiments. ${ }^{63,64}$ Therefore, INT1 is expected to be present for the dynamics recorded after $60 \mathrm{fs}$ in Figure 6. The subsequent relaxation of INT1 to the more stable INT1r and INT2 structures is predicted to occur over the next several hundred fs. These aci-nitro tautomer structures are predicted to have higher-frequency torsional vibrations $\left(86.9 \mathrm{~cm}^{-1}\right.$ for INT1, $61.0 \mathrm{~cm}^{-1}$ for INT1r, and $79.8 \mathrm{~cm}^{-1}$ for INT2, Figure 12) than the 2-NT cation at $47.9 \mathrm{~cm}^{-1}$. These results suggest that the faster $114 \mathrm{~cm}^{-1}$ oscillations observed in the $\mathrm{C}_{7} \mathrm{H}_{6} \mathrm{NO}^{+}$transient as compared to the $91 \mathrm{~cm}^{-1}$ oscillations of the parent $2-\mathrm{NT}^{+}$(Figure 6) may be attributed to the coherent torsional motion of the aci-nitro tautomer.

Additional insight into the dynamics of conversion from the initial INT1 aci-nitro tautomer to the INT1r and INT2 structures can be gained through analysis of the slowing oscillations of the $\mathrm{C}_{7} \mathrm{H}_{6} \mathrm{NO}^{+}$transient with increasing pump-probe delay as noted in Figure 6. The oscillatory component of the $\mathrm{C}_{7} \mathrm{H}_{6} \mathrm{NO}^{+}$signal from Figure 6 was fit to an exponen- 


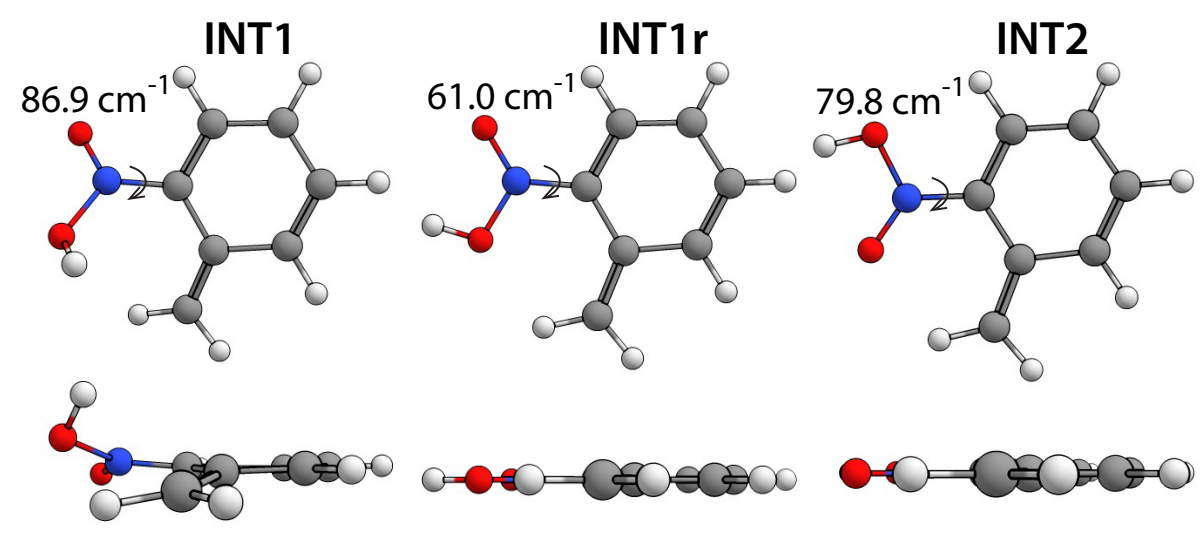

Figure 12: Aci structures.

tially decaying cosine function

$$
S(\tau)=a e^{-\tau / T} \cos (2 \pi f \tau+\phi)
$$

with frequency $f=115 \mathrm{~cm}^{-1}$ and phase $\phi=-0.97 \mathrm{rad}$, as well as an exponentially decaying linearly chirped cosine function

$$
S(\tau)=a e^{-\tau / T} \cos \left(2 \pi\left[f_{0} \tau+\frac{1}{2} k \tau^{2}\right]+\phi_{0}\right)
$$

with initial frequency $f_{0}=127 \mathrm{~cm}^{-1}$, chirp rate $k=0.972 \mathrm{ps}^{-2}$, and initial phase $\phi_{0}=-1.22$ rad.

The experimental $\mathrm{C}_{7} \mathrm{H}_{6} \mathrm{NO}^{+}$oscillatory signal fit to both eqs (2) (red) and (3) (blue) is shown in Figure 13. The dotted lines corresponding to the ion yield minima at $180 \mathrm{fs}, 470 \mathrm{fs}$, and 780 fs match to within \pm 2 fs of the minima in eq (3), while the second and third minima of eq (2) are 6 fs behind and 34 fs ahead of the experimental minima, respectively. The instantaneous frequency $f(\tau)$ according to eq (3) decreases from $121 \mathrm{~cm}^{-1}$ at 180 fs to 101 $\mathrm{cm}^{-1}$ at 780 fs. This $17 \%$ decrease in the instantaneous frequency is in between the $\sim 30 \%$ frequency decrease between INT1 and INT1r and the $8 \%$ decrease between INT1 and INT2 seen in Figure 12. Although the expected errors in computed frequencies preclude a direct comparison between the experimental and computed frequencies, the observed frequency 
decrease suggests that some mixture of INT1, INT1r, and INT2 structures are present by 780 fs after ionization.

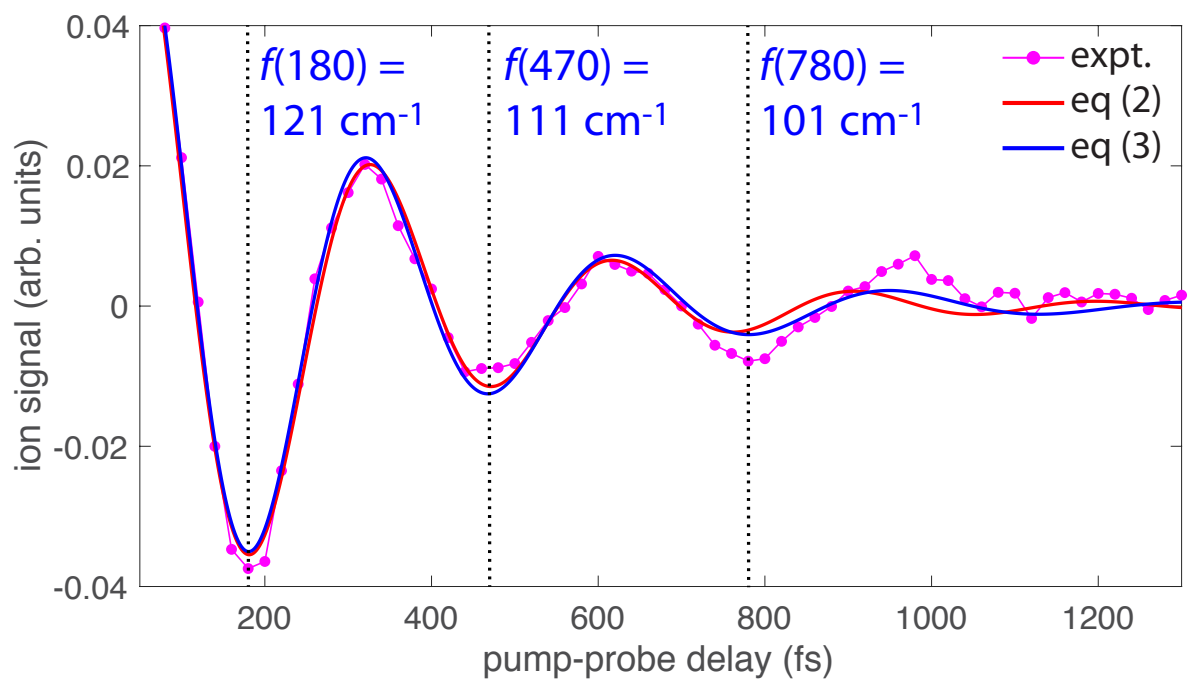

Figure 13: Oscillatory $\mathrm{C}_{7} \mathrm{H}_{6} \mathrm{NO}^{+}$ion signal (magenta dots) fit to eq (2) (red) and eq (3) (blue). Dotted lines indicate minima in the experimental ion yield.

The collective experimental and computational results discussed above provide substantial evidence that the observed slowing oscillations in the $\mathrm{C}_{7} \mathrm{H}_{6} \mathrm{NO}^{+}$product can be assigned to the coherent torsional motion of the aci-nitro tautomer and its conversion from the initially formed INT1 to more stable structures. This finding indicates that the initially-prepared vibrational coherence in the parent $2-\mathrm{NT}^{+}$ion is preserved following the H-atom attack that forms the aci-nitro tautomer. To the best of our knowledge, this result is the first report of conserved vibrational coherence upon intramolecular rearrangement in a radical cation, and builds on the results of Ref. ${ }^{64}$ showing conserved vibrational coherence following H-atom transfer in neutral excited 2-(2'-Hydroxyphenyl)benzothiazole. Previous studies have reported conserved vibrational coherence following internal conversion in excited cyclohexadiene, ${ }^{65}$ benzonitriles, ${ }^{66,67}$ Rydberg states of $N$-methyl morpholine, ${ }^{60,61}$ and azobenzene radical cation. ${ }^{38} \mathrm{CO}$ loss from excited-state metal hexacarbonyls has also been reported to result in coherent vibrational motion of the remaining metal pentacarbonyl. ${ }^{68-70}$ We attribute this unexpected behavior to the exceptionally fast H-atom attack within $\sim 20-60$ 
fs, which maintains the localized vibrational excitation along the torsional coordinate.

\subsection{Summary of $2-\mathrm{NT}^{+}$rearrangement and dissociation dynamics}

The experimental and theoretical results presented in the previous sections are combined to form our current understanding of $2-\mathrm{NT}^{+}$rearrangement and dissociation dynamics, presented in Figure 14. The black structure denotes the aci-nitro tautomer intermediate, while the colored structures correspond to the products indicated in Figures 3, 5, and 6. The colored arrows denote excitation by the pump (dark red) or probe (orange), the solid black arrows denote reaction pathways computed in Section 3.3, and the dotted arrows denote additional proposed pathways towards observed dissociation products. The reaction pathways labeled I through IV are summarized below.

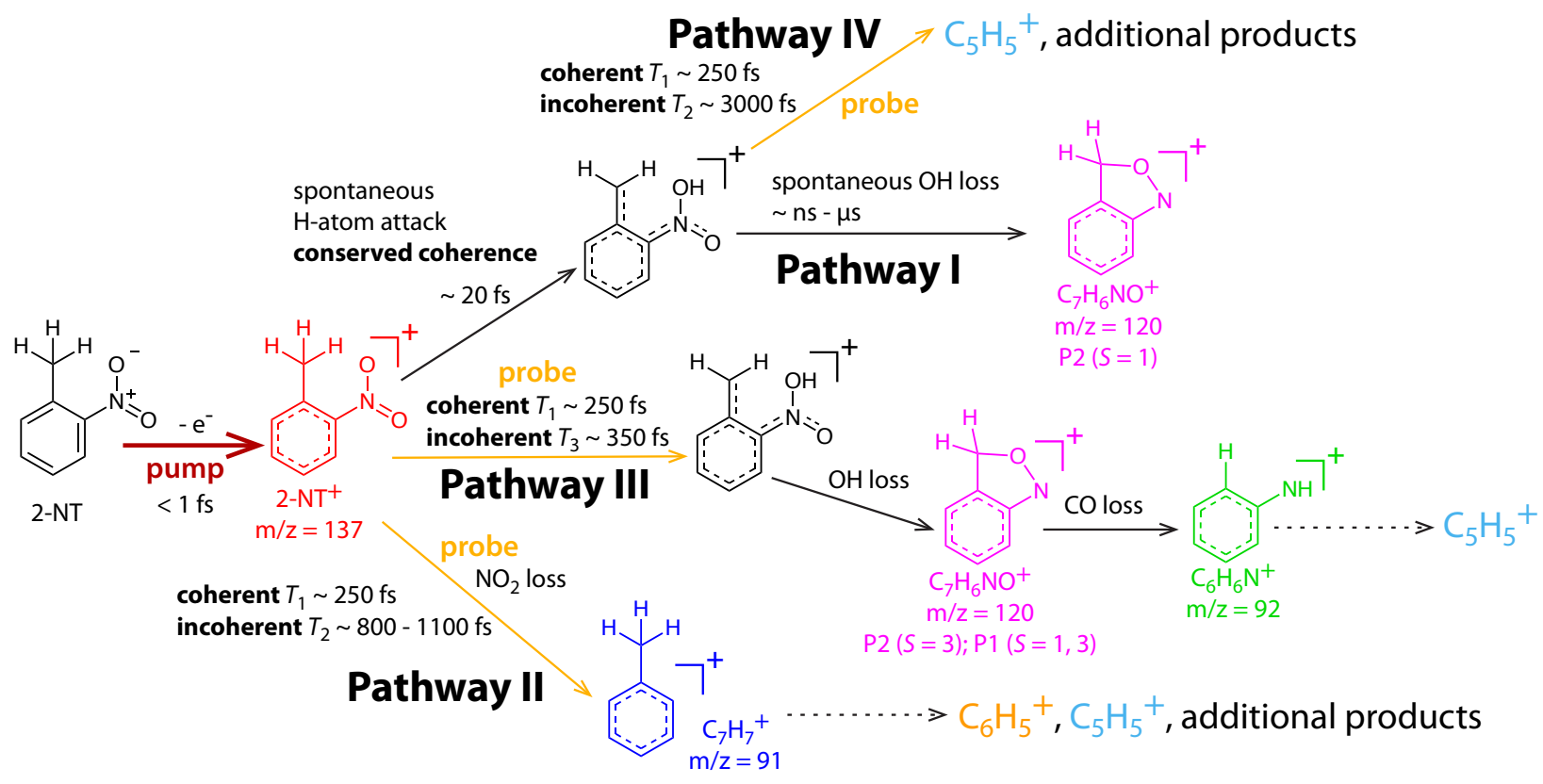

Figure 14: tentative dissociation pathway scheme

First, the pump pulse ionizes $2-\mathrm{NT}$ to produce $2-\mathrm{NT}^{+}$. In the absence of probe pulse excitation, a significant fraction of the ions produced undergo no further dissociation, producing the large peak at $\mathrm{m} / \mathrm{z}=137$ seen in Figure 3(a) at negative time-delay and denoted as the red parent ion in Figure 14. Much of the remaining parent ion population has sufficient energy 
to overcome the aci-rearrangement energy barrier of $0.76 \mathrm{eV}$ (Figure 8), which produces the aci-nitro tautomer as structure INT1 (Figure 8 ) as early as $\sim 20$ fs according to our ADMP simulations (Figure 9). The calculated reaction pathway shown in Figure 10 indicates that the aci-nitro tautomer is expected to spontaneously lose $\mathrm{OH}$ to form $\mathrm{C}_{7} \mathrm{H}_{6} \mathrm{NO}^{+}$at $\mathrm{m} / \mathrm{z}=$ 120 (magenta) via Pathway I in Figure 14. This pathway produces exclusively $\mathrm{C}_{7} \mathrm{H}_{6} \mathrm{NO}^{+}$ structure P2 with $S=1$ (Figure 10). The high yield of $\mathrm{m} / \mathrm{z}=120$ at negative time delays (Figure 3) is consistent with Pathway I requiring no probe excitation.

We next consider the pathways induced by excitation of the parent 2-NT ${ }^{+}$(red in Figure 14) structure with the probe pulse. Probe excitation can induce direct $\mathrm{NO}_{2}$ loss from the parent ion to produce $\mathrm{C}_{7} \mathrm{H}_{7}{ }^{+}(\mathrm{m} / \mathrm{z}=91$, blue, Pathway $\mathbf{I I})$. This direct dissociation pathway occurs following coherent probe excitation on the $T_{1}$ timescale of $\sim 250 \mathrm{fs}$ based on the observed oscillations, as well as the incoherent $T_{2}$ timescale of $800-1100$ fs (Tables 2 and 3). The $\mathrm{C}_{7} \mathrm{H}_{7}{ }^{+}$may further dissociate to form $\mathrm{C}_{6} \mathrm{H}_{5}{ }^{+}, \mathrm{C}_{5} \mathrm{H}_{5}{ }^{+}$, and other smaller products. In particular, the nearly perfect antiphase oscillations of $\mathrm{C}_{6} \mathrm{H}_{5}{ }^{+}$with the parent ion suggest that the coherent Pathway II can form this product. The additional sequential dissociation Pathway III involves first aci-rearrangement induced by probe excitation, followed by $\mathrm{OH}$ loss to form $\mathrm{C}_{7} \mathrm{H}_{6} \mathrm{NO}^{+}$(magenta) as structure $\mathrm{P} 1$ with $S=1,3$ and/or P2 with $S=3$ (Figure 10). A portion of this excited $\mathrm{C}_{7} \mathrm{H}_{6} \mathrm{NO}^{+}$undergoes subsequent $\mathrm{CO}$ loss to form $\mathrm{C}_{6} \mathrm{H}_{6} \mathrm{~N}^{+}$ (green). These species arise from an incoherent excitation pathway on the $T_{3}$ timescale of $\sim 350$ fs and could be formed as either singlet or triplet products (Figures $10-11$ ). It is worth noting that the $\mathrm{C}_{6} \mathrm{H}_{6} \mathrm{~N}^{+}$product also exhibits antiphase oscillations with the same frequency as the parent ion, suggesting that coherent excitation on the $T_{1}$ timescale can also initiate dissociation via Pathway III. However, the lack of corresponding oscillations at the same frequency and phase in the $\mathrm{C}_{7} \mathrm{H}_{6} \mathrm{NO}^{+}$product suggests that the coherently excited parent ion undergoes the full sequential dissociation shown in Pathway III to form $\mathrm{C}_{6} \mathrm{H}_{6} \mathrm{~N}^{+}$. Finally, the presence of the $T_{3}$ timescale in the $\mathrm{C}_{5} \mathrm{H}_{5}{ }^{+}$ion suggests that the $\mathrm{C}_{6} \mathrm{H}_{6} \mathrm{~N}^{+}$can undergo further dissociation to form this product. 
Finally, we consider the interaction of the spontaneously-formed aci-nitro tautomer with the probe pulse (Pathway IV). The coherent dynamics of this species discussed in Section 3.4 indicate that one or more dissociation products can be formed upon its coherent excitation. Based on the observed $\mathrm{C}_{5} \mathrm{H}_{5}{ }^{+}$oscillations being close to antiphase with the $\mathrm{C}_{7} \mathrm{H}_{6} \mathrm{NO}^{+}$ (Figure 6), it is likely that $\mathrm{C}_{5} \mathrm{H}_{5}{ }^{+}$is a significant product of aci-nitro tautomer excitation. Additionally, the observation that the oscillations in the $\mathrm{m} / \mathrm{z}=91$ product (assigned to $\left.\mathrm{C}_{7} \mathrm{H}_{7}{ }^{+}\right)$are somewhat shifted from antiphase with the parent ion suggests that an additional product with this $\mathrm{m} / \mathrm{z}$ value, i.e., $\mathrm{C}_{6} \mathrm{H}_{5} \mathrm{~N}^{+}$, may be formed by excitation of the aci-nitro tautomer. The presence of small amounts of $\mathrm{m} / \mathrm{z}=89$ and 90 (likely $\mathrm{C}_{6} \mathrm{H}_{3} \mathrm{~N}^{+}$and $\mathrm{C}_{6} \mathrm{H}_{4} \mathrm{~N}^{+}$) observable in Figure 3 suggests that such dissociation pathways involving the loss of one or more $\mathrm{H}$ atoms are possible.

\section{Conclusion}

Coherent vibrational dynamics in 2-NT radical cation were probed with strong-field adiabatic ionization with near-infrared pulses and cation excitation with visible pulses. Observed oscillations in ion yields with the pump-probe delay was attributed to the coherent excitation of the $\mathrm{C}-\mathrm{NO}_{2}$ torsional motion in the parent 2-NT cation. This vibrational coherence was found to be preserved upon spontaneous H-atom attack to form the aci-nitro tautomer based on the faster oscillations in the $\mathrm{C}_{7} \mathrm{H}_{6} \mathrm{NO}^{+}$ion formed by $-\mathrm{OH}$ loss from the aci-nitro tautomer structure. A series of DFT calculations both supported the assertion of preserved coherence in the aci-nitro tautomer and determined the H-atom attack mechanism involving three aci-nitro tautomer structures. The subsequent $-\mathrm{OH}$ and $-\mathrm{CO}$ loss pathways from the aci-nitro tautomer determined through DFT calculations found that these dissociation

reactions could produce both singlet and triplet $\mathrm{C}_{7} \mathrm{H}_{6} \mathrm{NO}^{+}$products. Collectively, these results provide a detailed picture of the coherent and incoherent excitation pathways in 2-NT radical cation that lead to the formation of multiple dissociation products. Future 
high-level calculations of ground- and excited-state potential energy surfaces in 2-NT cation and the aci-nitro tautomer, along with additional time-resolved measurements with different probe wavelengths, could provide further insight into the specific excited states accessed by the coherent excitation pathways observed in this work. Building on the present results, such additional studies could help develop efficient coherent control schemes for 2-NT and other nitroaromatic energetic molecules.

\section{Acknowledgement}

The authors acknowledge the support of the U.S. Army Research Office through Contract W911NF-18-1-0051 (KMT) and the U.S. Department of Energy, Office of Basic Energy Sciences, Division of Materials Sciences and Engineering under Award DE-FG02-96ER45579 (PJ).

\section{Supporting Information Available}

Laser pulse characterization, additional pump-probe data, tabulated theoretical results, magnified structures of intermediates, transition states, and dissociation products.

\section{References}

(1) Rajasekharan Pillai, V. N. Photoremovable Protecting Groups in Organic Synthesis. Synthesis 1980, 1980, 1-26.

(2) Gao, X.; Gulari, E.; Zhou, X. In Situ Synthesis of Oligonucleotide Microarrays. Biopolymers 2004, 73, 579-596.

(3) Ellis-Davies, G. C. R. Caged Compounds: Photorelease Technology for Control of Cellular Chemistry and Physiology. Nat. Methods 2007, 4, 619-628. 
(4) Sikder, A.; Sikder, N. A Review of Advanced High Performance, Insensitive and Thermally Stable Energetic Materials Emerging for Military and Space Applications. J. Hazard. Mater. 2004, 112, $1-15$.

(5) Weickhardt, C.; Tönnies, K. Short Pulse Laser Mass Spectrometry of Nitrotoluenes: Ionization and Fragmentation Behavior. Rapid Commun. Mass Spectrom. 2002, 16, $442-446$.

(6) McEnnis, C.; Dikmelik, Y.; Spicer, J. B. Femtosecond Laser-Induced Fragmentation and Cluster Formation Studies of Solid Phase Trinitrotoluene Using Time-of-Flight Mass Spectrometry. Appl. Surf. Sci. 2007, 254, 557 - 562.

(7) Sulzer, P.; Rondino, F.; Ptasinska, S.; Illenberger, E.; Märk, T. D.; Scheier, P. Probing Trinitrotoluene (TNT) by Low-Energy Electrons: Strong Fragmentation Following Attachment of Electrons Near 0 eV. Int. J. Mass Spectrom. 2008, 272, 149 - 153.

(8) Mullen, C.; Coggiola, M. J.; Oser, H. Femtosecond Laser Photoionization Time-ofFlight Mass Spectrometry of Nitro-Aromatic Explosives and Explosives Related Compounds. J. Am. Soc. Mass Spectrom. 2009, 20, 419-429.

(9) Cohen, R.; Zeiri, Y.; Wurzberg, E.; Kosloff, R. Mechanism of Thermal Unimolecular Decomposition of TNT (2,4,6-Trinitrotoluene): A DFT Study. J. Phys. Chem. A 2007, 111, 11074-11083.

(10) Wang, B.; Wright, D.; Cliffel, D.; Haglund, R.; Pantelides, S. T. Ionization-Enhanced Decomposition of 2,4,6-Trinitrotoluene (TNT) Molecules. J. Phys. Chem. A 2011, 115, $8142-8146$.

(11) Van, B. N.; Nikolaeva, E.; Shamov, A.; Khrapkovskii, G.; Tsyshevsky, R. Exploration of Decomposition Pathways of 2,4,6-Trinitrotoluene (TNT) Radical Ions by Means of Density Functional Theory. Int. J. Mass Spectrom. 2015, 392, 7 - 15. 
(12) Furman, D.; Kosloff, R.; Zeiri, Y. Mechanism of Intact Adsorbed Molecules Ejection Using High Intensity Laser Pulses. J. Phys. Chem. C 2016, 120, 11306-11312.

(13) Beynon, J. H.; Saunders, R. A.; Topham, A.; Williams, A. E. The Dissociation of o-Nitrotoluene Under Electron Impact. J. Chem. Soc. 1965, 0, 6403-6405.

(14) Shao, J.-D.; Baer, T. The Dissociation Dynamics of Energy Selected o-Nitrotoluene Ions. Int. J. Mass Spectrom. Ion Process. 1988, 86, $357-367$.

(15) Choe, J. C.; Kim, M. S. Photodissociation Kinetics of the P-Nitrotoluene Molecular Ion on a Nanosecond Time Scale. J. Phys. Chem. 1991, 95, 50-56.

(16) Simeonsson, J. B.; Lemire, G. W.; Sausa, R. C. Trace Detection of Nitrocompounds by ArF Laser Photofragmentation/Ionization Spectrometry. Appl. Spectrosc. 1993, 47, $1907-1912$.

(17) Kosmidis, C.; Marshall, A.; Clark, A.; Deas, R. M.; Ledingham, K. W. D.; Singhal, R. P.; Harris, F. M. Multiphoton Ionization and Dissociation of Nitrotoluene Isomers by UV Laser Light. Rapid Commun. Mass Spectrom. 1994, 8, 607-614.

(18) Kosmidis, C.; Ledingham, K. W. D.; Kilic, H. S.; McCanny, T.; Singhal, R. P.; Langley, A. J.; Shaikh, W. On the Fragmentation of Nitrobenzene and Nitrotoluenes Induced by a Femtosecond Laser at 375 nm. J. Phys. Chem. A 1997, 101, 2264-2270.

(19) Lozovoy, V. V.; Zhu, X.; Gunaratne, T. C.; Harris, D. A.; Shane, J. C.; Dantus, M. Control of Molecular Fragmentation Using Shaped Femtosecond Pulses. J. Phys. Chem. A 2008, 112, 3789-3812.

(20) Zhang, Q.; Fang, W.; Xie, Y.; Cao, M.; Zhao, Y.; Shan, X.; Liu, F.; Wang, Z.; Sheng, L. Photoionization and Dissociation Study of P-Nitrotoluene: Experimental and Theoretical Insights. J. Mol. Struct. 2012, 1020, 105 - 111. 
(21) Cao, M.; Li, Y.; Chu, G.; Chen, J.; Shan, X.; Liu, F.; Wang, Z.; Sheng, L. VUV Photoionization and Dissociation of o-Nitrotoluene: Experimental and Theoretical Insights. J. Electron. Spectros. Relat. Phenomena 2013, 191, 41 - 47.

(22) Ampadu Boateng, D.; Gutsev, G. L.; Jena, P.; Tibbetts, K. M. Dissociation Dynamics of 3- and 4-Nitrotoluene Radical Cations: Coherently Driven C-NO2 Bond Homolysis. J. Chem. Phys. 2018, 148, 134305.

(23) Wettermark, G. Photochromism of o-Nitrotoluenes. Nature 1962, 194, 677.

(24) Chen, S. C.; Xu, S. C.; Diau, E.; Lin, M. C. A Computational Study on the Kinetics and Mechanism for the Unimolecular Decomposition of o-Nitrotoluene. J. Phys. Chem. A 2006, 110, 10130-10134.

(25) Fayet, G.; Joubert, L.; Rotureau, P.; Adamo, C. A Theoretical Study of the Decomposition Mechanisms in Substituted o-Nitrotoluenes. J. Phys. Chem. A 2009, 113, $13621-13627$.

(26) Gudem, M.; Hazra, A. Intersystem Crossing Drives Photoisomerization in oNitrotoluene, a Model for Photolabile Caged Compounds. J. Phys. Chem. A 2018, 122, 4845-4853.

(27) Schmierer, T.; Laimgruber, S.; Haiser, K.; Kiewisch, K.; Neugebauer, J.; Gilch, P. Femtosecond Spectroscopy on the Photochemistry of Ortho-Nitrotoluene. Phys. Chem. Chem. Phys. 2010, 12, 15653-15664.

(28) Fröbel, S.; Gilch, P. Femtochemistry of Selected Di-Substituted Benzenes. J. Photochem. Photobiol. A 2016, 318, $150-159$.

(29) Pearson, B.; Nichols, S.; Weinacht, T. Molecular Fragmentation Driven by Ultrafast Dynamic Ionic Resonances. J. Chem. Phys. 2007, 127, 131101. 
(30) Nichols, S.; Weinacht, T.; Rozgonyi, T.; Pearson, B. Strong-Field Phase-Dependent Molecular Dissociation. Phys. Rev. A 2009, 79, 043407.

(31) Gonzalez-Vazquez, J.; Gonzalez, L.; Nichols, S. R.; Weinacht, T. C.; Rozgonyi, T. Exploring Wavepacket Dynamics Behind Strong-Field Momentum-Dependent Photodissociation in CH2BrI+. Phys. Chem. Chem. Phys. 2010, 12, 14203-14216.

(32) Geißler, D.; Marquetand, P.; González-Vázquez, J.; González, L.; Rozgonyi, T.; Weinacht, T. Control of Nuclear Dynamics with Strong Ultrashort Laser Pulses. J. Phys. Chem. A 2012, 116, 11434-11440.

(33) Zhu, X.; Lozovoy, V. V.; Shah, J. D.; Dantus, M. Photodissociation Dynamics of Acetophenone and Its Derivatives with Intense Nonresonant Femtosecond Pulses. J. Phys. Chem. A 2011, 115, 1305-1312.

(34) Konar, A.; Shu, Y.; Lozovoy, V. V.; Jackson, J. E.; Levine, B. G.; Dantus, M. Polyatomic Molecules under Intense Femtosecond Laser Irradiation. J. Phys. Chem. A 2014, $118,11433-11450$.

(35) Bohinski, T.; Tibbetts, K. M.; Tarazkar, M.; Romanov, D. A.; Matsika, S.; Levis, R. J. Strong Field Adiabatic Ionization Prepares a Launch State for Coherent Control. J. Phys. Chem. Lett. 2014, 5, 4305-4309.

(36) Tibbetts, K. M.; Tarazkar, M.; Bohinski, T.; Romanov, D. A.; Matsika, S.; Levis, R. J. Controlling the Dissociation Dynamics of Acetophenone Radical Cation Through Excitation of Ground and Excited State Wavepackets. J. Phys. B: At. Opt. Mol. Phys. 2015, 48, 164002 .

(37) Ho, J.-W.; Chen, W.-K.; Cheng, P.-Y. Femtosecond Pump-Probe PhotoionizationPhotofragmentation Spectroscopy: Photoionization-Induced Twisting and Coherent Vibrational Motion of Azobenzene Cation. J. Chem. Phys. 2009, 131, 134308. 
(38) Munkerup, K.; Romanov, D.; Bohinski, T.; Stephansen, A. B.; Levis, R. J.; Sølling, T. I. Conserving Coherence and Storing Energy during Internal Conversion: Photoinduced Dynamics of cis- and trans-Azobenzene Radical Cations. J. Phys. Chem. A 2017, 121, 8642-8651.

(39) Ampadu Boateng, D.; Gutsev, G. L.; Jena, P.; Tibbetts, K. M. Ultrafast Coherent Vibrational Dynamics in Dimethyl Methylphosphonate Radical Cation. Phys. Chem. Chem. Phys. 2018, 20, 4636-4640.

(40) Lezius, M.; Blanchet, V.; Rayner, D. M.; Villeneuve, D. M.; Stolow, A.; Ivanov, M. Y. Nonadiabatic Multielectron Dynamics in Strong Field Molecular Ionization. Phys. Rev. Lett. 2001, 86, 51-54.

(41) Lezius, M.; Blanchet, V.; Ivanov, M. Y.; Stolow, A. Polyatomic Molecules in Strong Laser Fields: Nonadiabatic Multielectron Dynamics. J. Chem. Phys. 2002, 117, 15751588.

(42) Ampadu Boateng, D.; Tibbetts, K. M. Measurement of Ultrafast Vibrational Coherences in Polyatomic Radical Cations with Strong-Field Adiabatic Ionization. JoVE 2018, 138, e58263.

(43) Gutsev, G. L.; Ampadu Boateng, D.; Jena, P.; Tibbetts, K. M. A Theoretical and Mass-Spectrometry Study of Dimethyl Methylphosphonate: New Isomers and Cation Decay Channels in an Intense Femtosecond Laser Field. J. Phys. Chem. A 2017, 121, 8414-8424.

(44) Kane, D. J.; Trebino, R. Characterization of Arbitrary Femtosecond Pulses Using Frequency-Resolved Optical Gating. IEEE J. Quant. Electron. 1993, 29, 571-579.

(45) Hankin, S. M.; Villeneuve, D. M.; Corkum, P. B.; Rayner, D. M. Intense-Field Laser Ionization Rates in Atoms and Molecules. Phys. Rev. A 2001, 64, 013405. 
(46) Frisch, M.; Trucks, G.; Schlegel, H.; Scuseria, G.; Robb, M.; Cheeseman, J.; Scalmani, G.; Barone, V.; Mennucci, B.; Petersson, G.; et al, Gaussian 09, Revision B. 01. 2016.

(47) Krishnan, R.; Binkley, J. S.; Seeger, R.; Pople, J. A. Self-Consistent Molecular Orbital Methods. XX. A Basis Set for Correlated Wave Functions. J. Chem. Phys. 1980, 72, $650-654$.

(48) Montgomery, J. A.; Frisch, M. J.; Ochterski, J. W.; Petersson, G. A. A Complete Basis Set Model Chemistry. VI. Use of Density Functional Geometries and Frequencies. J. Chem. Phys. 1999, 110, 2822-2827.

(49) Burke, K.; Perdew, J. P.; Wang, Y. In Electronic Density Functional Theory: Recent Progress and New Directions; Dobson, J. F., Vignale, G., Das, M. P., Eds.; Springer US: New York, 1998; pp 81-111.

(50) Becke, A. D. Density Functional Thermochemistry. III. The Role of Exact Exchange. J. Chem. Phys. 1993, 98, 5648-5652.

(51) Lee, C.; Yang, W.; Parr, R. G. Development of the Colle-Salvetti Correlation-Energy Formula into a Functional of the Electron Density. Phys. Rev. B 1988, 37, 785-789.

(52) Yanai, T.; Tew, D. P.; Handy, N. C. A New Hybrid Exchange-Correlation Functional Using the Coulomb-Attenuating Method (CAM-B3LYP). Chem. Phys. Lett. 2004, 393, $51-57$.

(53) Chai, J.-D.; Head-Gordon, M. Long-Range Corrected Hybrid Density Functionals with Damped Atom-Atom Dispersion Corrections. Phys. Chem. Chem. Phys. 2008, 10, $6615-6620$.

(54) Head-Gordon, M.; Pople, J. A.; Frisch, M. J. MP2 Energy Evaluation by Direct Methods. Chem. Phys. Lett. 1988, 153, $503-506$. 
(55) Bauernschmitt, R.; Ahlrichs, R. Treatment of Electronic Excitations Within the Adiabatic Approximation of Time Dependent Density Functional Theory. Chem. Phys. Lett. 1996, $256,454-464$.

(56) NIST Standard Reference Database 69. http://webbook.nist.gov/chemistry/, http://webbook.nist.gov/chemistry/. Last checked 10/05/18.

(57) Montgomery, J. A.; Frisch, M. J.; Ochterski, J. W.; Petersson, G. A. A Complete Basis Set Model Chemistry. VII. Use of the Minimum Population Localization Method. J. Chem. Phys. 2000, 112, 6532-6542.

(58) Fukui, K. The Path of Chemical Reactions - The IRC Approach. Acc. Chem. Res. 1981, 14, 363-368.

(59) Schlegel, H. B.; Iyengar, S. S.; Li, X.; Millam, J. M.; Voth, G. A.; Scuseria, G. E.; Frisch, M. J. Ab Initio Molecular Dynamics: Propagating the Density Matrix with Gaussian Orbitals. III. Comparison with Born-Oppenheimer Dynamics. J. Chem. Phys. 2002, 117, 8694-8704.

(60) Waters, M. D. J.; Skov, A. B.; Larsen, M. A. B.; Clausen, C. M.; Weber, P. M.; Sølling, T. I. Symmetry Controlled Excited State Dynamics. Phys. Chem. Chem. Phys. 2019, DOI: 10.1039/C8CP05950K, in press.

(61) Zhang, Y.; Jónsson, H.; Weber, P. M. Coherence in Nonradiative Transitions: Internal Conversion in Rydberg-Excited N-methyl and N-ethyl Morpholine. Phys. Chem. Chem. Phys. 2017, 19, 26403-26411.

(62) Shishkov, I. F.; Vilkov, L. V.; Kovács, A.; Hargittai, I. Molecular Geometry of 2Nitrotoluene from Gas Phase Electron Diffraction and Quantum Chemical Study. J. Mol. Struct. 1998, 445, $259-268$. 
(63) Herek, J. L.; Pedersen, S.; Bañares, L.; Zewail, A. H. Femtosecond Real-Time Probing of Reactions. IX. Hydrogen-Atom Transfer. J. Chem. Phys. 1992, 97, 9046-9061.

(64) Lochbrunner, S.; Wurzer, A. J.; Riedle, E. Ultrafast Excited-State Proton Transfer and Subsequent Coherent Skeletal Motion of 2-(2'-Hydroxyphenyl)benzothiazole. J. Chem. Phys. 2000, 112, 10699-10702.

(65) Kosma, K.; Trushin, S. A.; Fuß, W.; Schmid, W. E. Cyclohexadiene Ring Opening Observed with 13 fs Resolution: Coherent Oscillations Confirm the Reaction Path. Phys. Chem. Chem. Phys. 2009, 11, 172-181.

(66) Yatsuhashi, T.; Trushin, S.; Fuß, W.; Rettig, W.; Schmid, W.; Zilberg, S. Ultrafast Charge Transfer and Coherent Oscillations in 4-Piperidino-Benzonitrile. Chem. Phys. 2004, 296, $1-12$.

(67) Fuß, W.; Schmid, W. E.; Kuttan Pushpa, K.; Trushin, S. A.; Yatsuhashi, T. Ultrafast Relaxation and Coherent Oscillations in Aminobenzonitriles in the Gas Phase Probed by Intense-Field Ionization. Phys. Chem. Chem. Phys. 2007, 9, 1151-1169.

(68) Trushin, S.; Fuß, W.; Schmid, W. Conical Intersections, Pseudorotation and Coherent Oscillations in Ultrafast Photodissociation of Group-6 Metal Hexacarbonyls. Chem. Phys. 2000, 259, $313-330$.

(69) Trushin, S.; Kosma, K.; Fuß, W.; Schmid, W. Wavelength-Independent Ultrafast Dynamics and Coherent Oscillation of a Metal-Carbon Stretch Vibration in Photodissociation of $\mathrm{Cr}(\mathrm{CO})_{6}$ in the Region of 270-345 nm. Chem. Phys. 2008, 347, $309-$ 323.

(70) Kosma, K.; Trushin, S. A.; Fuß, W.; Schmid, W. E.; Schneider, B. M. R. Photodissociation of Group-6 Hexacarbonyls: Observation of Coherent Oscillations in an Antisymmetric (Pseudorotation) Vibration in $\mathrm{Mo}(\mathrm{CO})_{5}$ and $\mathrm{W}(\mathrm{CO})_{5}$. Phys. Chem. Chem. Phys. 2010, 12, 13197-13214. 


\section{TOC Graphic}

$\mathrm{H}$-atom attack:

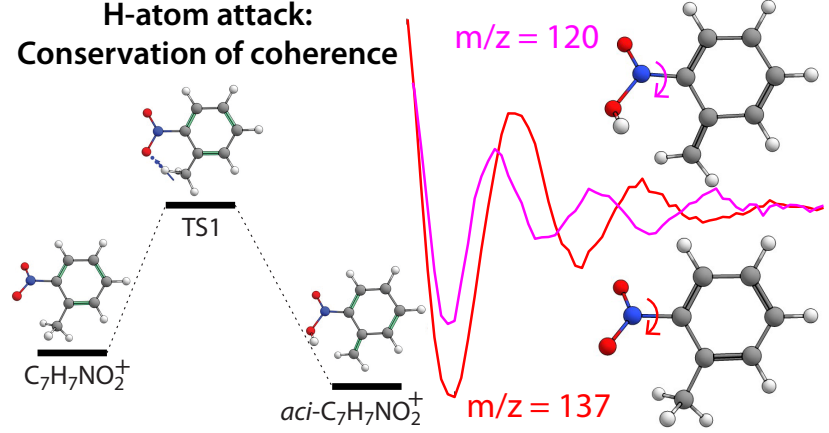

